\title{
Energy valorisation of food processing residues and model compounds by hydrothermal liquefaction
}

\author{
Maxime Déniel ${ }^{\mathrm{a}, \mathrm{b}, *}$, Geert Haarlemmer ${ }^{\mathrm{a}}$, Anne Roubaud ${ }^{\mathrm{a}}$, \\ Elsa Weiss-Hortala ${ }^{\mathrm{b}}$, Jacques Fages ${ }^{\mathrm{b}}$ \\ ${ }^{a}$ CEA-LITEN/Laboratoire de Thermo-conversion des Bioressources, 17 rue des Martyrs, 38054 Grenoble Cedex 9, France \\ ${ }^{\mathrm{b}}$ Université de Toulouse, Ecole des Mines d'Albi, CNRS Centre RAPSODEE, 81013 Albi, France
}

Keywords:

Hydrothermal liquefaction

Food processing residues

Bio-oil

Subcritical water

Biomass conversion

\begin{abstract}
A B S T R A C T
The upcoming depletion of fossil fuels calls for the development of alternative energies produced from renewable resources. Particularly, energy valorisation of agriculture and food processing wastes is one of the most promising tools for renewable energy production. The amount of food wastes is rapidly increasing due to urbanisation, industrialisation and population growth worldwide. They consequently represent a widely available resource, and their use as a raw material allows reducing the environmental cost associated with their disposal. These resources usually have high moisture content, making dry valorisation processes unattractive because of a costly drying step prior to conversion. Hydrothermal processes are conversely particularly well suited for the valorisation of wet organic wastes in an eco nomical way, since they use water as the reaction medium. More specifically, liquid fuels can be pro duced using hydrothermal liquefaction (HTL). The process converts wet biomass into a crude like oil with

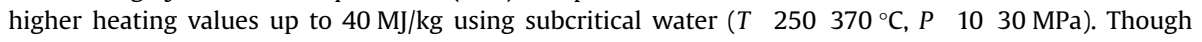
this is an active research area, the mechanisms of hydrothermal liquefaction still remain unclear today. Some processes have already been developed at the pilot scale for valorising food processing wastes. However, the development of HTL processes at industrial scales is facing technological and economic challenges. This paper discusses the two main issues to address for development of the process at large scales. On the one hand, hydrothermal conversion of food processing residues and model compounds is necessary to better understand the fundamentals of hydrothermal liquefaction. As well, technological and process integration issues have to be addressed to ensure economic viability of commercial HTL processes.
\end{abstract}

\section{Contents}

1. Introduction: hydrothermal liquefaction is a promising tool for renewable energy production $\ldots \ldots \ldots \ldots \ldots \ldots$

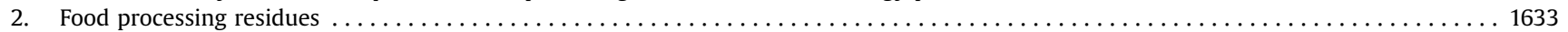

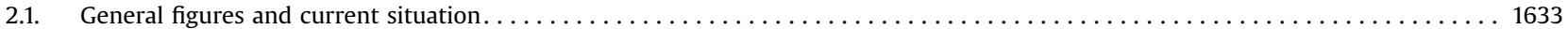

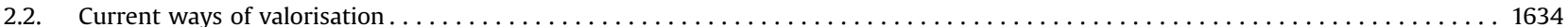

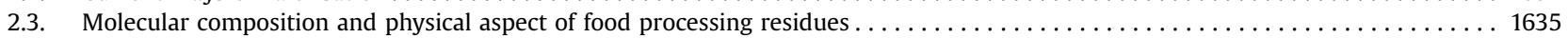

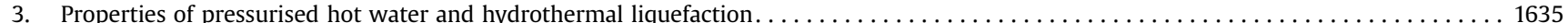

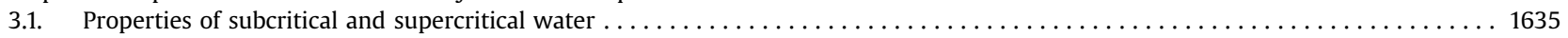

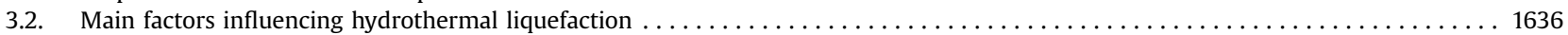

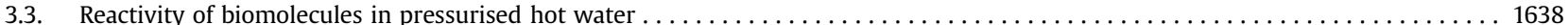

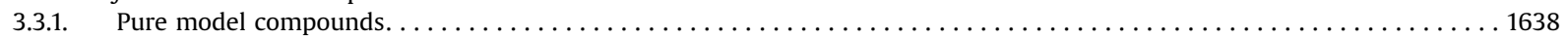

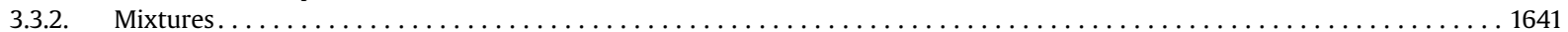

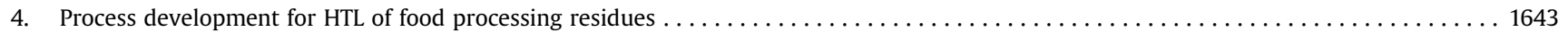

* Corresponding author at: CEA-LITEN/Laboratoire de Thermo-conversion des Bioressources, 17 rue des Martyrs, 38054 Grenoble Cedex 9, France. Tel.: + 33 438784026; fax: +33438785251 .

E-mail address: maxime.deniel@cea.fr (M. Déniel). 


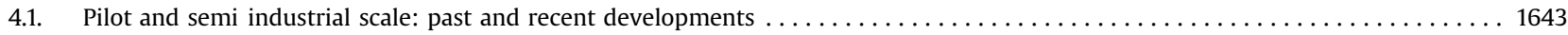

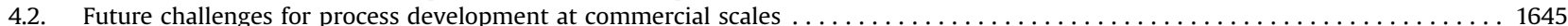

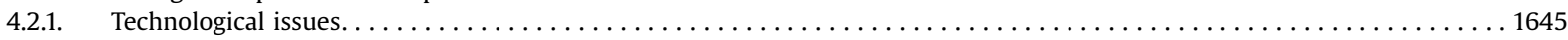

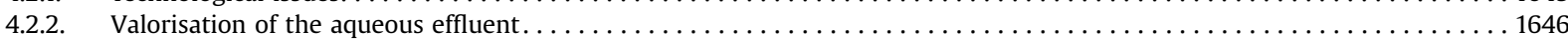

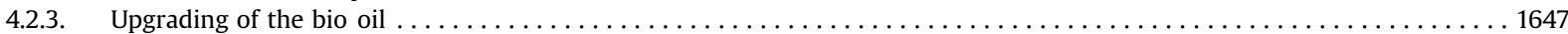

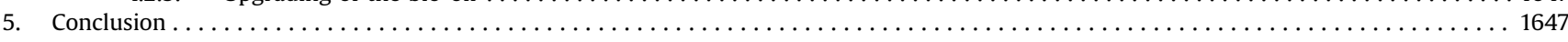

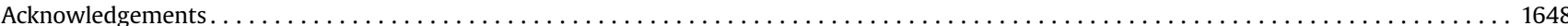

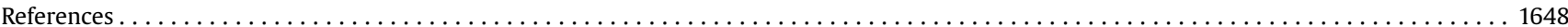

\section{Introduction: hydrothermal liquefaction is a promising tool for renewable energy production}

Access to sustainable energy is a strategic issue in our modern societies, becoming more and more important as the world population is growing. Our economies are based on fossil resour ces such as coal and crude oil, which represent more than $80 \%$ of the energy production in the world [1]. The exploitation of such non renewable resources will lead to a rise in prices, and to depletion of fossil fuels within a few decades. In addition, the rise in environmental concerns and legislations call for new, cleaner and economical ways to meet our needs for energy and products. For the future, there is no other alternative than using renewable resources. Nowadays, renewable energies represent less than $20 \%$ of the global energy demand worldwide. However, the share of renewables in the global energy supply is expected to increase at about $30 \%$ by 2035 [1].

Among the many sources of renewable energies, biomass is sometimes described as a "sleeping giant" because of its high availability around the world, associated with a still limited valorisation, especially for energy production. The main advantage of using biomass is that it is a carbon neutral source of energy, since the $\mathrm{CO}_{2}$ produced during combustion had been previously converted into organic matter by the process of photosynthesis. Organic wastes from agriculture and food processing industries have traditionally been reused to a large extent. However, the amount of food wastes is rapidly increasing due to urbanisation, industrialisation and population growth worldwide. They conse quently represent a widely available source for valorisation, and modern centralised production techniques make it interesting to consider organic wastes for energy production. In addition, using organic wastes as a raw material allows reducing the environ mental cost associated with their disposal. Their management is of crucial importance since they can cause environmental problems: contribution to the greenhouse effect by methane and carbon dioxide emissions, contamination of soils and groundwater and human health issues.

Food processing wastes have gained a growing interest in recent years, due to their potential for recovering high value compounds. Many processes are being developed for reusing food wastes in an efficient and environmentally friendly way. Useful materials are either obtained as such from extraction or separation processes, or produced by waste transformation. On the one hand, several recent techniques based on extraction using supercritical fluids, which are generally considered as green and safe solvents, have recently emerged. Details on the different processes for extracting high value additives for food and pharmaceutical industries can be found in recent reviews [2,3], and will not be discussed in this paper. On the other hand, many biochemical and thermochemical processes are currently being developed to participate in tomorrow's energy supply, by converting biomass into renewable fuels. The main bio logical food processing waste to energy processes are anaerobic digestion to produce biogas for heat and electricity production, and bioethanol production by sugar fermentation [4]. Among thermochemical technologies, such as pyrolysis to produce liquid bio oils, the majority of processes require a biomass with relatively low moisture content, generally less than $30 \mathrm{wt} \%$ : they are therefore not adapted to wet biomass. In this context, hydrothermal processes are promising leads for the valorisation of wet organic wastes in an economical way, since they use water as both a reaction medium and reactant. Wet biomass in particular can be directly transformed into liquid fuels by hydrothermal liquefaction.

Energy valorisation of wet biomass through hydrothermal processes is an active research area, and many review papers have been published in the past fifteen years. Table 1 provides an overview of the review papers published in the field of hydro thermal processes and hydrothermal liquefaction (HTL). Various aspects are reported: some are interested in fundamental prop erties of water in the sub and supercritical region as well as in the chemistry associated; while others report advances on every hydrothermal process. Certain articles focus specifically on hydrothermal liquefaction, even though they relate in majority to algae based bio refineries. Other review papers aim at comparing various conversion routes for producing renewable liquid fuels from wet biomass, but these papers are also related to HTL of micro and macro algae.

With this paper, we therefore intend to focus specifically on hydrothermal liquefaction applied to food processing residues. By providing information on the complete process chain, from the initial resources to issues related to process development, we aim to give a comprehensive overview of the production of renewable liquid fuels from food processing wastes by hydrothermal liquefaction (HTL).

Starting from the current situation and current ways of valor isation, we have reviewed HTL applied to food processing residues and model compounds. A special emphasis is given to the effect of process parameters, and to the nature and molecular composition of food processing residues. Extensive information is provided regarding the reactivity of model compounds in subcritical water, as such fundamental information is required to fully understand results from HTL experiments. Finally, we underline the main limitations to the industrialisation of hydrothermal liquefaction, therefore giving leads for future work.

\section{Food processing residues}

As introduced previously, food processing residues are of great interest for the future energy mix. In this section, we define first the nature and amount of food processing residues which could be potentially valorised. Secondly, we detail the current ways of valorisation of these wastes. Finally, the molecular composition is described, as it is a key point for further valorisation.

\subsection{General figures and current situation}

Food wastes correspond to different categories and are gener ated at every stage of the food supply chain. For instance, food wastes generated during purchase, preparation and consumption 
Table 1

List of review papers dealing with hydrothermal technologies [5-38].

\begin{tabular}{ll}
\hline Focus of the review & References \\
\hline $\begin{array}{c}\text { Properties of subcritical and supercritical } \\
\text { water, chemical reactions }\end{array}$ & Akiya and Savage [5] \\
& Weingärtner and Franck [6] \\
& Kruse and Dinjus [7], Kruse and \\
& Dinjus [8] \\
& Yu et al. [9] \\
& Brunner [10] \\
& Savage [11] \\
& Möller et al. [12] \\
& Jin and Enomoto [13] \\
& Simsek Kus [14] \\
& Kang et al. [15] \\
& Kruse and Dahmen [16] \\
& Peterson et al. [17] \\
& Biller and Ross [18] \\
& Kruse et al. [19] \\
& Pavlovič et al. [20] \\
& Yeh et al. [21] \\
Ruiz et al. [22] & Tekin et al. [23] \\
Hydrothermal processes (mentioning HTL et al. [24] & Patil et al. [25] \\
Toor et al. [26] \\
Akhtar and Amin [27] \\
Tekin and Karagöz [28] \\
biofuels production & López Barreiro et al. [29] \\
& Tian et al. [30] \\
& Elliott et al.[31] \\
Xiu and Shahbazi [32] \\
Chow et al. [33] \\
Marcilla et al. [34] \\
Milledge et al. [35] \\
Chen et al. [36] \\
Chen et al. [37] \\
Chen et al. [38] \\
\hline \\
\\
\end{tabular}

of meals are considered as post consumer wastes: they are mainly influenced by the consumers' behaviour and cooking habits. On the other hand, food processing wastes are mostly pre consumer wastes, produced during the transformation of animal and vegetal material for animal feed and human consumption. The agricultural sector produces wastes as sub products (e.g. straw) but also as damaged products considered as non marketable. As well, food industries are accountable for a great portion of waste generation due to problems during transport, storage, processing or packa ging [39]. Food processing residues are available under a wide variety of forms. They are for example fruit and vegetable pro cessing wastes (e.g. fruit pomace), wastes from meat and fish industries (e.g. carcasses, blood, bones and fats), winery and brewery wastes, aqueous phases (e.g. whey), sludge from waste water treatment and singular forms such as empty fruit bunches of oil palm trees.

Each year, a huge quantity of wastes is generated along the food supply chain: based on data from the year 2007, the Food and Agriculture Organization (FAO) estimated that 1.6 billion tons per year are lost, which represents more than $20 \%$ of the total world agricultural production, and about one third of the total world food production for human nutrition [40]. Depending on the industry, the proportion of generated wastes varies: approxi mately $30 \mathrm{wt} \%$ of cereals, $4050 \mathrm{wt} \%$ of root crops, fruits and vegetables, $20 \mathrm{wt} \%$ of oilseeds, meat and dairy products, and $35 \mathrm{wt} \%$ of fish are lost $[40,41]$. The amount of food wastes is rapidly increasing due to urbanisation, industrialisation and population growth worldwide. It is expected to grow even more in future years. For instance, food wastes in the European Union are expected to grow from 89 million tons in 2006 to 126 million tons in 2020 [42].
Food and agricultural wastes are therefore abundant, cheap and renewable resources. The valorisation of the large amount of food processing residues generated each year is an issue of the utmost importance, because bad management of these wastes can con tribute to environmental problems: contribution to the green house effect by methane and carbon dioxide emissions, con tamination of soils and groundwater and human health issues. It is also necessary to put into perspective the important amount of wet organic wastes produced by food industries with the increasingly limited space available for storage, which speaks in favour of the development of alternative ways of valorisation. This constitutes an opportunity for material and energy valorisation, and to develop a bio based economy. Management of food pro cessing wastes requires important means for sorting, treating and valorising this material, with the objective of reducing the envir onmental cost associated with their disposal.

\subsection{Current ways of valorisation}

When considering the valorisation of food processing residues, two main aspects have to be taken into account: the processes and the applications. Thus, it is important to determine the nature of the secondary raw materials which could be obtained. In fact, this feature will importantly determine the type of processes needed to valorise the feedstock.

Currently, several ways of valorising food processing residues exist, such as animal feed, soil fertilizer or combustion. For instance, fruit and vegetable wastes (e.g. peels, shells and seeds) are currently used as animal feed or fertilizer. However, disposal of wet organic wastes in landfills can cause important emissions of methane $\left(\mathrm{CH}_{4}\right)$ and carbon dioxide $\left(\mathrm{CO}_{2}\right)$, which are important greenhouse gases, thus contributing to climate change. Meat and fish processing wastes (e.g. blood, fat, bones...) are used to pro duce bone meal that is burnt, used as fertilizer or in animal feed, leading to major sanitary problems in the past. The current ways of valorising food processing residues are therefore associated with environmental and human health issues, underlining the need for cleaner and better ways of valorisation. Even if they are discarded as wastes, food processing residues contain a lot of valuable compounds, from sugars to bioactive compounds, among others. For example, lignin rich wastes can be used for recovery of phe nolic compounds, since it is the only renewable source of such compounds. They have consequently valuable properties for sev eral industries, such as food and pharmaceutical industries, resins and adhesives, or even to enhance stability of biofuels [43 46]. As well, lignin contained in fruit and vegetable processing residues contributes to more than half of the heating value in biomass, and can then be valorised as energy carrier. Meat processing wastes contain many lipids which are products of interest for the food industry, as well as for renewable energies. In recent years, an increase of the use of edible oils has been observed around the world because of change in the diet of emerging countries as well as the rise in biodiesel production. Using lipid rich wastes can contribute to meet the needs for such products, either by extrac tion to recover valuable fatty acids or direct conversion into bio based fuels.

Due to the potential of food processing residues for recovering valuable compounds and renewable fuels, the key issue is to use suitable processes regarding both the nature of these wastes and the application expected. Considering the production of renewable fuels, many biochemical and thermochemical processes are cur rently being developed to participate in tomorrow's energy supply. Particularly, several processes can be used to convert biomass into liquid fuels. Biochemical processes use micro organisms or enzymes at moderate temperatures to carry out specific reactions. The main biological food processing waste to energy processes 
are anaerobic digestion to produce biogas for heat and electricity production, and bioethanol production by sugar fermentation [4]. Even though they are attractive to treat wet resources, they also have some limitations. For instance, fermentation of wet resources often requires an expensive hydrolysis step to produce fermen table sugars prior to fermentation. Anaerobic digestion requires expensive post treatment steps such as purification of the biogas. Finally, both processes use microorganisms which are highly sensitive to any kind of changes in the operating conditions (temperature, $\mathrm{pH}$, presence of inhibitors...), leading to decreased performances. For instance, using lignin rich substrates can lead to inhibition of enzymatic hydrolysis, therefore decreasing the global performance of the process [47].

On the contrary, thermochemical processes are not limited by the biomass composition. These processes use high temperature chemical reactions to convert biomass into gas, solid or liquid fuels. Many technologies exist, such as direct combustion to gen erate heat and electricity, gasification to produce synthesis gas, or pyrolysis to produce liquid bio oils. However, all of these processes need a biomass with relatively low moisture content, generally less than $30 \mathrm{wt} \%$, They are therefore not adapted to wet biomass such as food processing residues with moisture contents higher than $95 \mathrm{wt} \%$ in some cases. Consequently, 'dry' processes are often unattractive, because of the costly drying of the biomass before further processing, along with high transport costs and environ mental issues. In this context, thermochemical conversion routes for wet organic wastes, namely hydrothermal processes, are pro mising leads for energy valorisation of such resources in an eco nomical way, since they use water as both a reaction medium and a reactant. Hydrothermal processes allow applying to wet resources the same processes as for dry routes: carbonisation, liquefaction and gasification. The whole biomass is converted into energy dense products, either in solid, liquid or gaseous forms. The production of liquid fuels by thermochemical processing is driven by the conversion temperature of the molecules contained in biomass. It is therefore necessary to know the initial composi tion of the raw waste, as well as the composition of the final products of interest.

\subsection{Molecular composition and physical aspect of food processing residues}

Food processing residues are available under a wide variety of forms. Wastes produced by the food processing industries vary from fruit and vegetable wastes (e.g. fruit pomace), aqueous phases (e.g. whey from dairy industries), sludge from wastewater treatment, wastes from meat and fish industries (e.g. carcasses, blood, bones and fats), winery and brewery wastes, to singular forms such as empty fruit bunches of oil palm trees. Food pro cessing residues contain a large variety of molecules, such as fibres, proteins and lipids among others, which are the basic building blocks of living cells.

Fibres are important contributors to the dry matter content of food processing residues, mainly generated by the fruit and vegetable processing industries. They are also found in algae, and in forestry and agricultural wastes. Fibres are structural macro molecules of vegetal cell walls, mainly based on three polymers: cellulose, hemicellulose and lignin. In vegetal cells, the fibres are intertwined with each other to give structure and robustness to the plant: hemicelluloses are linked to cellulose through hydrogen bonds, and lignin forms hydrogen and covalent bonds with cel lulosic polymers to give rigidity to the cell walls. Therefore, the composition as well as the energy of intermolecular bonds may affect depolymerisation and conversion of fibres into fuels.

Proteins are polymers of amino acids linked together by pep tide bonds. They are also found in food processing residues, mostly in meat and fish processing wastes and in some seeds. Many amino acids are valuable compounds for industries such as phar maceutical and cosmetics. As well, they can be converted into bio oils, yet increasing the nitrogen content of the products.

Lipids correspond to a broad variety of substances, such as fats, oils and waxes. They are mainly found as triglycerides in biomass, formed by up to $98 \mathrm{wt} \%$ of $C_{12}$ to $C_{18}$ fatty acids such as lauric, myristic, palmitic, stearic, oleic and linoleic acids. In food proces sing residues, lipids are mainly found in residues from seeds processing (olive, nuts...), meat processing wastes and in some fruit processing residues. Lipids are product of interest for the production of bio oils, mainly due to the long chain fatty acids that contribute to increase the amount and quality of the products.

Molecules contained in food processing residues have great chemical differences. Depending on the nature of each molecule, the amount and quality of bio oils produced can be directly affected. For instance, lipids greatly contribute to bio oil produc tion, while proteins can be valorised for other applications. In addition, interactions can form by products, either contributing to the production of bio oils or reducing it. Studies on the reactivity of each type of compounds individually and in mixtures are therefore necessary. In fact, the identification of reaction mechanisms and kinetics is the first step of optimising the process of producing liquid fuels from food wastes.

\section{Properties of pressurised hot water and hydrothermal liquefaction}

As mentioned previously, the focus of this paper is hydro thermal liquefaction of food processing wastes. In the following sections, the properties of water in the subcritical and supercritical regions are briefly reminded, prior to the presentation of the main influencing parameters of the process. Finally, the reactivity of model molecules in the conditions of hydrothermal liquefaction is detailed.

\subsection{Properties of subcritical and supercritical water}

Hydrothermal processes avoid the need to dry the biomass before further processing, which can lead to big energy savings on the global energy consumption of the conversion process. Hydro thermal processes use the variations of the properties of water at high temperatures and pressures. In particular, water above its critical point $\left(T_{\mathrm{c}}=374{ }^{\circ} \mathrm{C}, P_{\mathrm{c}}=22.1 \mathrm{MPa}\right)$ acquires specific proper ties: variable density, gas like viscosity and increased diffusivity compared to liquid water. Subcritical water corresponds to pres surised liquid water at temperatures between its atmospheric boiling point and its critical temperature. Fig. 1 shows the phase diagram of water, as well as its variations of density, dielectric constant and ionic product with temperature. In the subcritical region, water loses its polarity, behaving similar as an organic solvent, while its ionic product $\mathrm{K}_{\mathrm{w}}$ increases up to three orders of magnitude. These variations in the properties of water lead to better solubility of organic compounds and increased catalytic activities for acid base reactions such as hydrolysis of the bio polymers contained in biomass [6].

Various hydrothermal processes for biomass conversion exist, depending on operating conditions, as illustrated in Fig. 2. At low temperatures $\left(150250^{\circ} \mathrm{C}\right.$ ) and pressures around $2.5 \mathrm{MPa}$, hydro thermal carbonisation (HTC) generates a solid phase valuable as a solid fuel, or for agricultural or energy storage purposes. At slightly higher temperatures and pressures, Aqueous Phase Reforming (APR) produces $\mathrm{H}_{2}$ in situ that reacts through heterogeneous cata lytic reactions to hydrogenate degradation products of biomass. Beyond the critical point, Supercritical Water Gasification (SCWG) is 

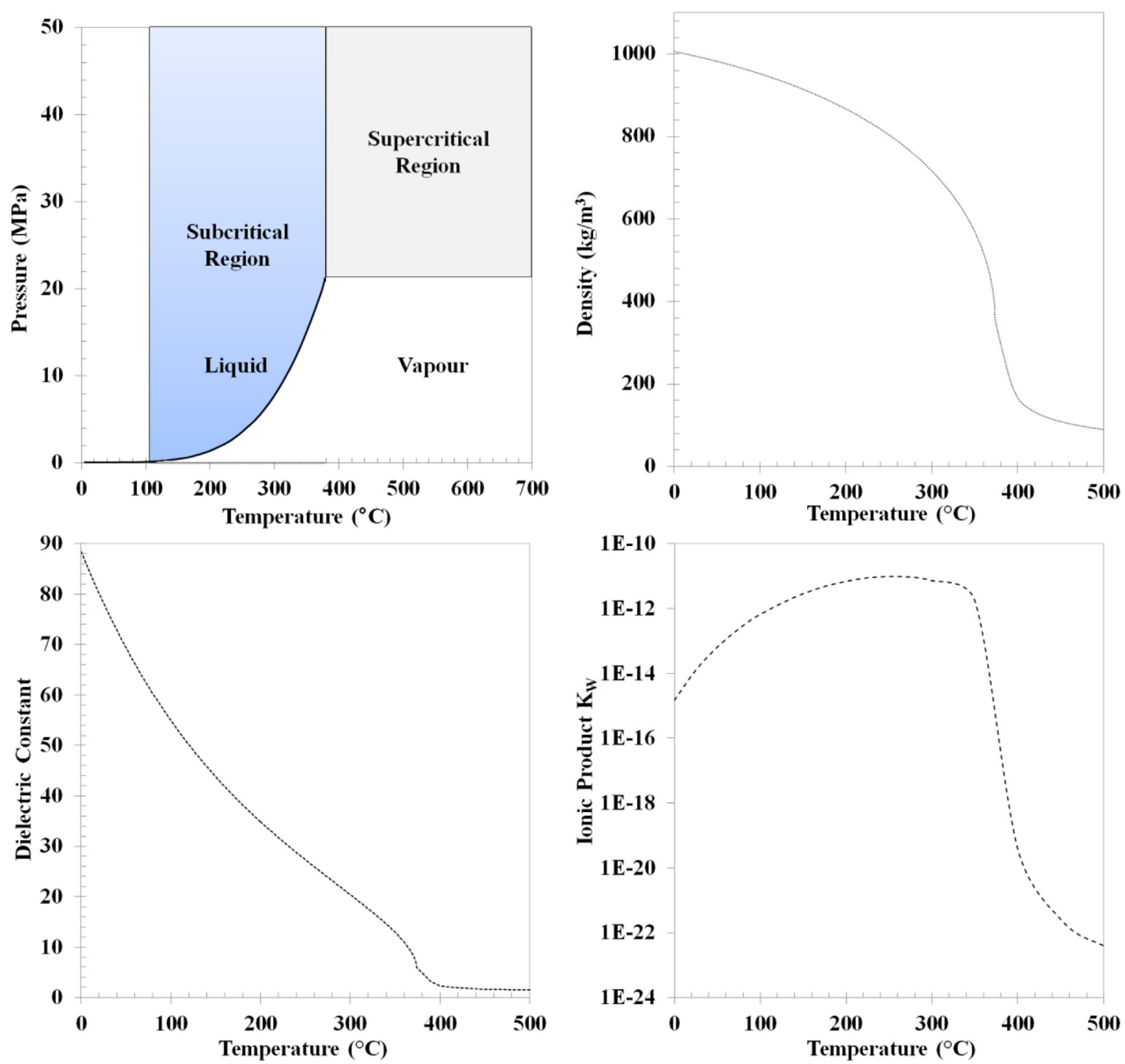

Fig. 1. Phase diagram of water and evolution of water properties at $P \quad 25 \mathrm{MPa}$ as a function of temperature.

favoured, leading to a combustible gas: methane riche in the near critical region, hydrogen rich at temperatures above $600^{\circ} \mathrm{C}$. Between 250 and $370{ }^{\circ} \mathrm{C}$ and at pressures above the equilibrium vapour pressure of water, an energy dense bio oil can be obtained by hydrothermal liquefaction (HTL).

\subsection{Main factors influencing hydrothermal liquefaction}

Hydrothermal liquefaction, commonly referred to as HTL, is a process in which wet biomass is converted into a crude like oil using subcritical water $\left(T=250370^{\circ} \mathrm{C}, P=1030 \mathrm{MPa}\right)$. In sub critical water, molecules contained in biomass are subjected to many degradation and condensation pathways, leading typically to the formation of 4 phases: an oily product known as 'bio oil' with higher heating values (HHV) up to $3540 \mathrm{MJ} / \mathrm{kg}$, an aqueous phase containing dissolved polar organics, a solid residue called 'char' and a $\mathrm{CO}_{2}$ rich gaseous phase. Despite their high availability and potential for valorisation, a limited number of studies have focused to date on hydrothermal liquefaction of food processing residues. A much larger number of papers report HTL applied to micro algae
[29], or forestry and agricultural wastes [48 65]. In the field of food processing residues, HTL was effectively applied to wastes from meat industries such as offal [66,67], carcasses [68] or manure [69 72]. As well, hydrothermal liquefaction of fish pro cessing residues was reported [73 75]. Other studies report hydrothermal liquefaction of fruit and vegetable processing resi dues [76 82], real food as a model for food wastes [83,84] or municipal wastes [84 87]. The vast majority of HTL studies have been carried out at the laboratory scale in closed vessels called autoclaves, running in batch mode. These studies mainly report the influence of different biomass compositions, as well as the influence of process parameters on the bio oil yield. The main product of interest in HTL processes is bio oil. Table 2 shows a comparison between various properties of bio oils and traditional fossil fuels.

Unlike pyrolysis oils, bio oils obtained by HTL have low moisture content and higher heating values up to $40 \mathrm{MJ} / \mathrm{kg}$, which make them interesting from an energy perspective. The properties of the bio oils depend on parameters such as the initial feedstock, 


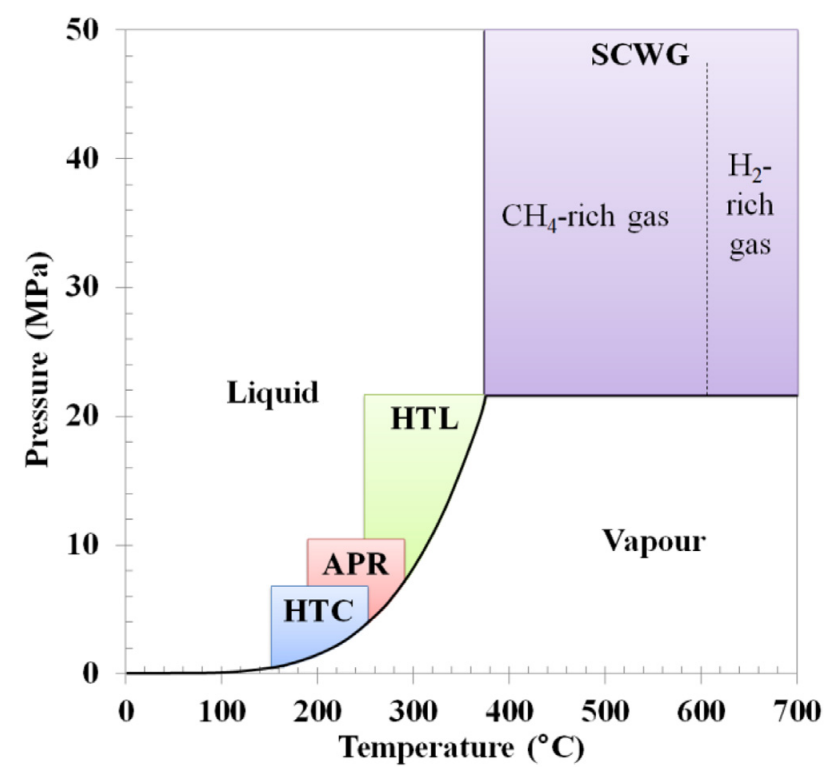

Fig. 2. Phase diagram $(P, T)$ of water and associated hydrothermal processes (adapted from [19], with permission from Elsevier).

Table 2

Comparison of properties of bio-oils and fossil fuels [26,70,88-93].

\begin{tabular}{|c|c|c|c|c|}
\hline & $\begin{array}{l}\text { Hydrothermal } \\
\text { liquefaction Oil }\end{array}$ & Pyrolysis Oil & Gasoline & $\begin{array}{l}\text { Domestic } \\
\text { heating oil }\end{array}$ \\
\hline \multicolumn{5}{|l|}{$\begin{array}{l}\text { Elemental com- } \\
\text { position (wt\% } \\
\text { on dry) }\end{array}$} \\
\hline $\mathrm{C}$ & $60-80$ & $55-70$ & $85-88$ & 86.5 \\
\hline $\mathrm{H}$ & $5-10$ & $5-10$ & $12-15$ & 13.3 \\
\hline $\mathrm{O}$ & $10-20$ & $35-50$ & 0 & Traces \\
\hline $\mathrm{N}$ & $0-5$ & $0-1$ & Traces & $\begin{array}{l}50- \\
400 \mathrm{ppm}\end{array}$ \\
\hline S & $<1$ & $<1$ & Traces & $<0.2$ \\
\hline $\begin{array}{l}\text { Moisture content } \\
\text { (wt\%) }\end{array}$ & $<10$ & 25 & - & $0.2-1.5$ \\
\hline $\begin{array}{l}\text { Higher Heating } \\
\text { Value }(\mathrm{MJ} / \mathrm{kg})\end{array}$ & $30-40$ & $16-23$ & 46.5 & 43 \\
\hline Viscosity (mPa s) & $40-210\left(60^{\circ} \mathrm{C}\right)$ & $15.6\left(40^{\circ} \mathrm{C}\right)$ & $\begin{array}{l}0.3-0.4 \\
\left(20^{\circ} \mathrm{C}\right)\end{array}$ & $\begin{array}{l}7.9-8.4 \\
\left(20^{\circ} \mathrm{C}\right)\end{array}$ \\
\hline
\end{tabular}

operating conditions as well as post conversion steps for bio oil recovery, which are discussed in this section.

The composition and structure of biomass influences the dis tribution of products. The amount of solid residue recovered during HTL of biomass is strongly correlated to the lignin content: the higher the lignin content in the biomass, the more char recovered. This is mainly due to the chemical robustness of lignin and to condensation reactions between unstable intermediates leading to polyaromatic structures [94 96]. On the other hand, cellulose and hemicelluloses contained in the biomass mainly produce char and water soluble molecules such as sugars, acids, ketones, aldehydes, furan and phenol derivatives. The lipid and protein contents of the biomass are important for increasing the bio oil yield, because they form long chain aliphatic molecules such as fatty acids, fatty acids alkyl esters and amides, as well as nitrogen heterocycles [86,97]. The bio oil yield depends on the chemical nature of the biomass, but process parameters such as temperature and residence time also have an influence on the distribution of products.
While a temperature under $280^{\circ} \mathrm{C}$ leads to incomplete degrada tion of biopolymers and negligible bio oil yields, a large number of papers report the existence of an optimum temperature near $300^{\circ} \mathrm{C}$ for most substrates [27]. Increasing the temperature allows a complete depolymerisation, and further fragmentations and condensations generate heavy hydrophobic compounds found in the bio oil. Yet, above the optimum temperature, the bio oil yield decreases in favour of the solid residue and the gas phase: radical reactions become predominant at higher temperatures, leading to polymeric structures found in the char and to small fragments in the gas phase. Reaction time also has an influence on the bio oil yield: longer reaction times lead to higher yields of solid residue and gas. Temperature and reac tion time are actually coupled, because higher temperatures increase reaction rates, including secondary reactions.

To avoid undesired secondary reactions, additives can be used. Studies on the influence of additives have mainly been focused on the use of alkali catalysts and reducing species to stabilise reaction intermediates, and inhibit secondary condensation reactions responsible for increasing the amount of polymeric char. Alkali catalysts such as $\mathrm{NaOH}$ and $\mathrm{Na}_{2} \mathrm{CO}_{3}$ are usually used to reduce the char yield and enhance bio oil formation [26,51,56]. Mechanisms behind experimental observations when using alkali catalysts are still unclear, even though one major effect is considered to be the catalysis of the water gas shift reaction [98], as well as dec arboxylation of fatty acids and decarbonylation of sugars $[99,100]$. The latter reactions improve the quality of bio oils, because they remove oxygen from the bio oil through $\mathrm{CO}_{2}$ formation, therefore without removing hydrogen. In all cases, the supply of hydrogen in the reaction medium is necessary to stabilise reactive inter mediates. The reducing effect provided by alkali catalysts can also be obtained when using process gases such as $\mathrm{H}_{2}, \mathrm{CO}$ or synthesis gas $[70,101]$. Yin et al. [70] reported the effect of several process gases on HTL of swine manure, and observed an increase of the bio oil yield by using $\mathrm{CO}$ and $\mathrm{H}_{2}$. Yet, the effect of such gases is sometimes considered as negligible by some authors, who underline the need for heterogeneous catalysts to compensate for bad mass transfer between phases [27]. To make up for these issues, alternative solvents can be used, either as substitutes for water or as co solvents. Hydrogen donor solvents such as tetralin are often used, because they are easy to handle and do not create any gas liquid phase boundary limitation in the reaction medium. Even if organic solvents from fossil resources are currently used, a recent study showed the feasibility of using bio based solvents as substitutes for tetralin [87].

Bio oils obtained by hydrothermal liquefaction are complex mixtures formed by hundreds of compounds with varying mole cular weights, such as carboxylic acids, alcohols, aldehydes, ketones, esters, sugars, phenol and furan compounds. It is usually necessary to use an organic solvent to recover the bio oil. Many organic solvents have been used in the literature: dichlor omethane is by far the most used solvent, either alone $[70,71,85,102$ 107] or in combination with less polar solvents [108 110]. Other solvents are chloroform [111,112], acetone $[92,113]$, tetrahydrofuran [83] or alkanes and aromatic compounds $[101,112]$. Even though rarely considered in the literature, the choice of extraction solvents can directly affect the amount and quality of the bio oil $[112,114,115]$. The polarity of the solvent will impact the type of molecules recovered in the bio oil. Gas chro matography coupled with Mass Spectrometry (GC MS) is the most used method to analyse HTL bio oils. However, the complexity of the mixtures makes difficult the exhaustive identification of the composition. In addition, this technique only provides partial information, because it often cannot identify molecules with high boiling points [112]. Analysis of HTL bio oils is therefore a chal lenge that calls for combination of techniques and development of specific analytical tools. 
Hydrothermal liquefaction is therefore a complex process depending on many parameters, leading to a wide number of reaction products. Even though the main parameters of influence have been identified through phenomenological approaches, mechanisms behind hydrothermal liquefaction are still unclear: studies on model compounds are needed to simplify the systems and allow the identification of reaction pathways and kinetics.

\subsection{Reactivity of biomolecules in pressurised hot water}

Food processing residues contain many different molecules. The global conversion efficiency depends consequently on the reaction mechanisms of each compound. Due to the complex composition of each feedstock, a global reaction scheme, including kinetic aspects, would be very difficult to achieve. This section addresses therefore a review of the reactions encountered during HTL of pure model compounds and some of their mixtures.

\subsubsection{Pure model compounds}

3.3.1.1. Fibres. Cellulose was extensively studied in the literature, and several reaction mechanisms have already been suggested: above $250{ }^{\circ} \mathrm{C}$, cellulose is rapidly hydrolysed to produce oligo saccharides and glucose [96,116 120]. Depending on the tem perature, hydrolysis of cellulose occurs following two different mechanisms, either heterogeneous in the subcritical region or homogeneous in the near critical and supercritical region [116,121 123]. As shown in Fig. 3, increasing the temperature and pressure increases the solubility of cellulose in water, leading to faster hydrolysis rates [116,120,122 124].

Secondary reactions of glucose lead to a diversification of reaction products, following three main mechanisms: retro aldol condensation which breaks $C$ C bonds, acid catalysed dehydration to produce furanic compounds and isomerisation to produce fructose known as Lobry de Bruyn Alberda Van Ekenstein trans formation [125 127]. Other secondary reactions lead to phenolic compounds, light polar molecules such as aldehydes, ketones and carboxylic acids, and gaseous products such as $\mathrm{CO}_{2}$ and light hydrocarbons [83]. Fig. 4 illustrates the many degradation path ways of glucose in subcritical water $[128,129]$.
HTL of cellulose generates a complex mixture of solid, liquid and gaseous products, mainly formed by light polar water soluble molecules and char. For instance, Pavlovič et al. [130] reported a maximum of $21 \%$ oil yield for HTL of cellulose at $250{ }^{\circ} \mathrm{C}$ during $60 \mathrm{~min}$. The many competitive pathways are influenced by oper ating conditions such as temperature, reaction time and $\mathrm{pH}$. For instance, an increase in temperature will enhance gas formation by decarboxylation and decarbonylation [130,131]. In addition, reaction times longer than a few minutes lead to an increased formation of carboxylic acids, as well as increased condensation reactions of reactive intermediates in the aqueous phase and in the bio oil, producing polymeric char $[132,133]$. To inhibit the formation of char, additives such as reducing gases $\left(\mathrm{CO}, \mathrm{H}_{2}\right)$ and alkali catalysts can be used. Acidic conditions favour dehydration of monosaccharides and cellulose as well as polymerisation reac tions, increasing therefore char formation [106,134,135]. On the other hand, high $\mathrm{pH}$ values favour retro aldol condensations, leading to $\mathrm{C}_{3} \mathrm{C}_{4}$ polar molecules. Consequently, high $\mathrm{pH}$ values decrease the bio oil and char yields in favour of the aqueous phase and the formation of carboxylic acids [106]. The two competing mechanisms can both be taking place at neutral $\mathrm{pH}$ values.

In comparison with cellulose, hemicelluloses are more sensitive to hydrolysis: they are rapidly hydrolysed at temperatures above $180^{\circ} \mathrm{C}$, while a minimum temperature of $250^{\circ} \mathrm{C}$ is necessary to initiate cellulose hydrolysis [136 138]. In biomass, amorphous regions are hydrolysed first, giving access to more crystalline regions. As illustrated in Fig. 5, monosaccharides generated by hydrolysis of hemicelluloses have a similar reactivity as hexoses [125,139 142].

Substituents of hemicelluloses can influence the reactivity. While acyl substituents produce acetic acid able to catalyse depolymerisation of long chain polysaccharides [143], uronic acids are responsible for lowering reaction rates of hydrolysis reactions [144]. A very limited number of studies focus on HTL of hemi celluloses, probably because their reactivity is similar to the reactivity of cellulose. For instance, Gao et al. [145] reported a low bio oil yield of $11.61 \mathrm{wt} \%$ for HTL of xylan at $300{ }^{\circ} \mathrm{C}$ during $30 \mathrm{~min}$.

Contrarily to hemicelluloses, numerous studies focused on hydrothermal conversion of lignin. As illustrated in Fig. 6, several reaction mechanisms were established as soon as the 1980s
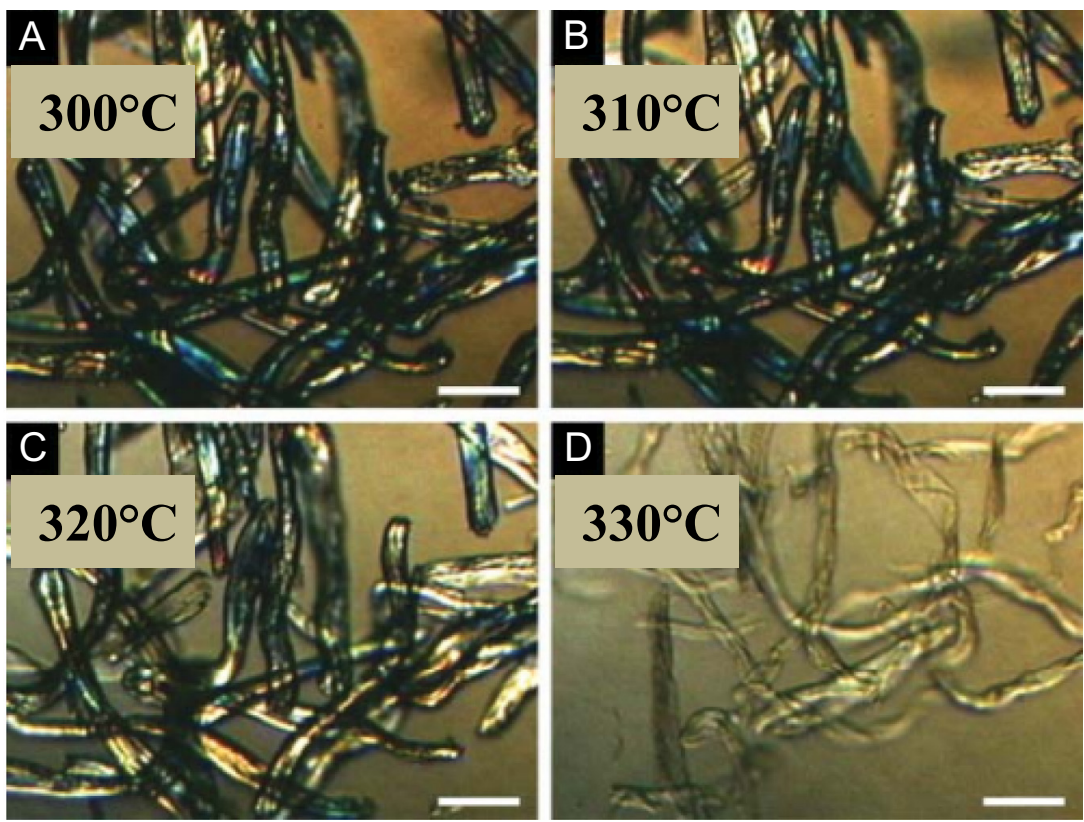

Fig. 3. Cellulose dissolution in water between $300^{\circ} \mathrm{C}$ and $330^{\circ} \mathrm{C}$ at $P \quad 25 \mathrm{MPa}$ (Reproduced from [122], with permission of The Royal Society of Chemistry). 

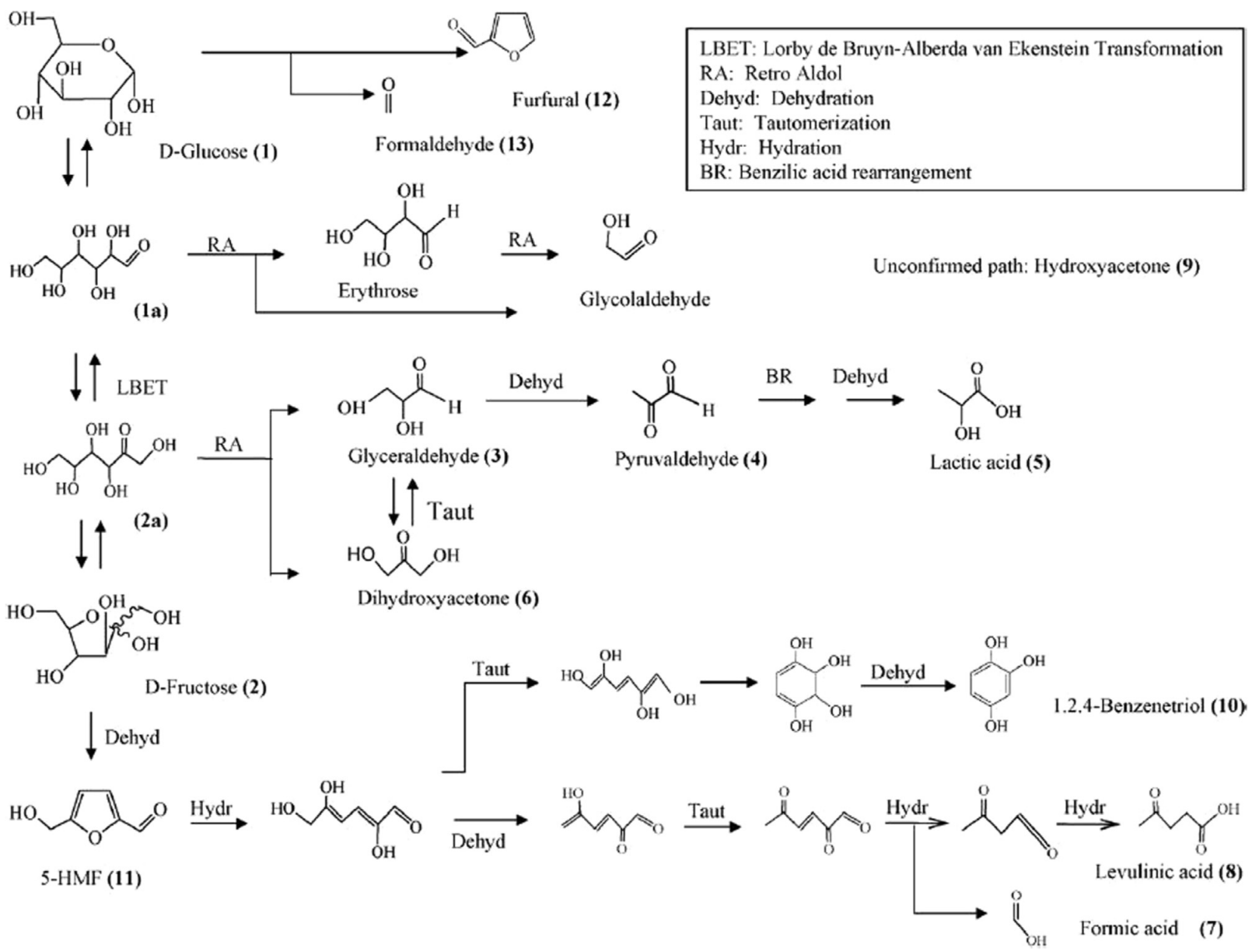

Fig. 4. Reaction mechanism of D-Glucose and D-Fructose in hydrothermal conditions (Reprinted from [128], with permission from Elsevier).

[79,146 151]. Particularly, studies on model compounds were conducted to identify reaction mechanisms and kinetics [148,152 161]. In hydrothermal conditions, lignin is first hydrolysed above $200{ }^{\circ} \mathrm{C}$ to produce mainly phenolic oligomers and monomers, which react through hydrolysis of methoxy groups, breakage of $C$ $\mathrm{C}$ bonds, alkylations and condensations. While aromatic rings are relatively stable, fragmentations of side chains of lignin produce carboxylic acids, alcohols and aldehydes [148,162, 163].

HTL of lignin mainly generates water soluble phenolic compounds and an insoluble solid residue, which can account for up to $90 \mathrm{wt} \%$ of the initial lignin $[79,152,159,164]$. Char formation was even observed when using monomeric model compounds such as guaiacol, which means it cannot be avoided during HTL of lignin $[154,156]$.

Density of the reaction medium is considered as the key parameter for HTL of lignin: increasing the density of water would enhance lignin conversion, because the ionic product of water increases with pressure. Therefore, density can be modulated to inhibit condensations and enhance fragmentation reactions, shifting the char formation to bio oil production [165,166]. Finally, increasing the temperature drives secondary reactions such as hydrolysis of methoxy groups and alkylations of phenolic com pounds, while increasing the reaction time allows the degradation of heavy molecular structures $[148,149,158,167]$.

The use of additives such as phenol can drastically reduce the proportion of solid residue $[150,151,165]$. Okuda et al. [150] reported only $1 \mathrm{wt} \%$ char yield after hydrothermal conversion of lignin in pre sence of phenol: according to the authors, phenol enhances frag mentation reactions and inhibits repolymerisation. Other co solvents have been used, such as ethanol $[168,169]$ or model compounds of lignin $[52,160]$. As well, homogeneous alkali catalysts such as potas sium salts $\left(\mathrm{K}_{2} \mathrm{CO}_{3}, \mathrm{KOH}\right)$ and sodium salts $\left(\mathrm{Na}_{2} \mathrm{CO}_{3}, \mathrm{NaOH}\right)$ can be used to promote base catalysed conversion of lignin, enhance the forma tion of phenol derivatives and inhibit repolymerisation reactions leading to solid residue $[51,170]$. In addition, some papers report the use of heterogeneous catalysts to improve hydrolysis of the ether bonds and stabilise phenolic monomers [161,171].

3.3.1.2. Proteins. Hydrothermal conversion of proteins starts with hydrolysis of the peptide bond, leading to the release of amino acids in the reaction medium. Even if it is slower than cellulose hydrolysis, hydrolysis of the peptide bond can benefit from the use of acid catalysts such as $\mathrm{CO}_{2}$ or $\mathrm{HCl}$ to increase the hydrolysis rate $[120,172]$, as well as base catalysts such as $\mathrm{NaOH}$ to recover amino acids [172]. Abdelmoez et al. [173] reported that most of the amino acids were stable at high $\mathrm{pH}$ values, while they showed lower stability at acidic and neutral $\mathrm{pH}$ values. Basic hydrolysis of the peptide bond produces a carboxylate ion instead of a carboxylic acid, therefore not affecting the amino groups. Because amino acids are high value molecules for the food and pharmaceutical industries, the majority of studies focus on the recovery of these building blocks from protein rich resources or model proteins: meat and fish processing wastes [73 75, 174 176], cereal wastes [177] or model compounds such as silk protein [172], soy protein

[178] and bovine serum albumin [120,179,180].

Amino acids degrade rapidly in subcritical water above $300{ }^{\circ} \mathrm{C}$ and produce mainly water soluble molecules: amines and $\mathrm{CO}_{2}$ by 


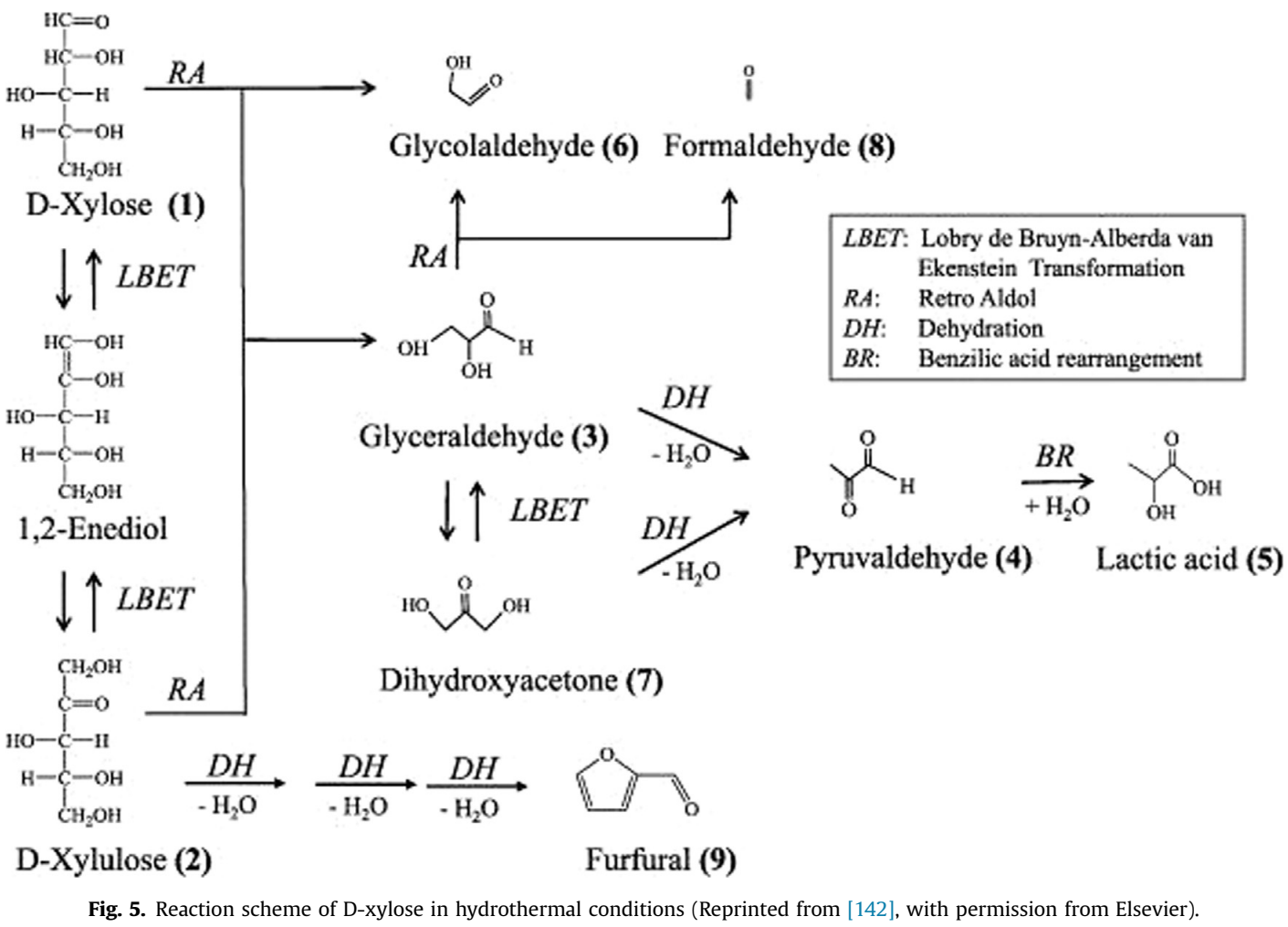

decarboxylation, carboxylic acids and $\mathrm{NH}_{3}$ by deamination $[176,179]$. Those two main reaction pathways have been identified in the literature by studies on two main model compounds: gly cine and alanine [181 184]. In addition, degradation of complex amino acids can lead to the formation of simpler amino acids: for instance, glycine and alanine can be produced by degradation of serine $[73,173,183,185]$. Increasing temperature and reaction time leads to an increase of the degradation reactions.

Hydrothermal liquefaction of proteins usually results in a low bio oil yield: Dote et al. [186] obtained $10 \mathrm{wt} \%$ bio oil yield after $\mathrm{HTL}$ of egg albumin at $300{ }^{\circ} \mathrm{C}$ during $2 \mathrm{~h}$, and comparable yields with amino acids used as model compounds [187]. Consequently, HTL of pure proteins mainly produces a nitrogen rich aqueous phase. However, better yields are obtained when using protein rich resources such as micro algae $[107,108,110]$, onion wastes [77], fermentation wastes [91], grains [78] and yeasts [109]. This can be partly explained by the recombination reactions of degra dation products above $300^{\circ} \mathrm{C}$ to form molecules contributing to the bio oil yield, such as phenol, indole, pyrrole, pyrazine and pyridine. As well, interactions with other molecules of biomass can contribute to increase the amount of bio oil.

3.3.1.3. Lipids. Triglycerides are rapidly hydrolysed above $280^{\circ} \mathrm{C}$ producing fatty acids and glycerol. The reaction was first described as a three step equilibrium by Mills and McClain [188], in which the first hydrolysis step is rate limiting. Some studies showed that hydrolysis of lipids is autocatalysed by fatty acids [189,190]. In addition, studies on fatty acid esters used as model compounds showed that hydrolysis can be catalysed either by $\mathrm{H}^{+}$or $\mathrm{OH}$ at extreme $\mathrm{pH}$ values, and even by $\mathrm{H}_{2} \mathrm{O}$ at neutral $\mathrm{pH}$ values [191 195]. The reaction is mainly influenced by temperature and by the ratio lipid/water. While the reaction rate increases with temperature, increasing the water amount results in better yields of fatty acids at equilibrium. The reaction mainly takes place in the oil phase, which means that the hydrolysis rate is limited by the mass transfer of water towards the oil phase [196 199].

Fatty acids are generally considered stable under $300{ }^{\circ} \mathrm{C}$. Above this temperature, decarboxylation of fatty acids generates alkanes, alkenes or ketones. The main focus of research papers is on the decarboxylation reaction, and additives can be used to drive reaction mechanism towards decarboxylation of fatty acids: alkali catalysts, metal oxides or supported noble metal catalysts can influence the selectivity of the reaction $[99,200]$.

HTL of lipids was recently studied by several authors who used model compounds, such as sunflower oil [97,107], corn oil [201], soybean oil [189], butter [202] and castor oil [97]. Bio oil yields up to $9095 \mathrm{wt} \%$ are generally obtained, associated with very low amounts of solid residue. Biller and Ross [107] showed that the bio oil is mainly formed by fatty acids and fatty acid esters using GC MS analysis.

Glycerol is the by product of triglycerides hydrolysis. In sub critical water, it produces mainly water soluble organics, driving the hydrolysis equilibrium towards higher conversion of trigly cerides. Long and Fang [203] reviewed the main reactions of gly cerol in hydrothermal conditions, as illustrated in Fig. 7. Glycerol is also used for co liquefaction of biomass, due to its solvent effect. Furthermore, crude glycerol (mixture of glycerine, methanol, soaps and catalysts) generated as a by product of biodiesel production can be valorised as a co substrate, solving at the same time eco nomic and environmental issues associated with biodiesel pro duction $[90,204$ 206].

Studies on pure model compounds in the conditions of hydro thermal liquefaction evidenced the wide number of reactions occur ring when pure model compounds are converted. After hydrolysis of biopolymers, many degradation pathways such as fragmentations, condensations and dehydrations lead to a wide variety of products in the bio oil, char, gas and aqueous phases. Real resources have a diverse and complex chemical composition, containing many different molecules. Interactions between either these molecules or their degradation products can also occur in the conditions of hydrothermal 


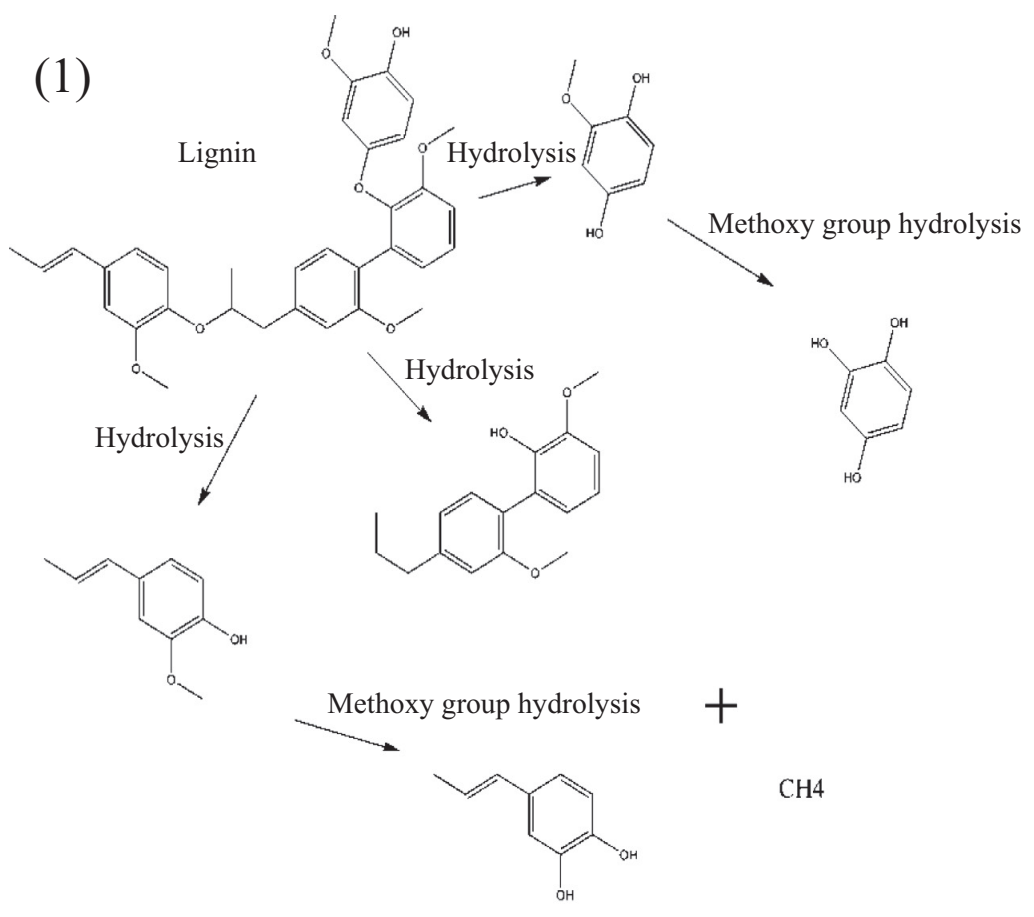

(2)
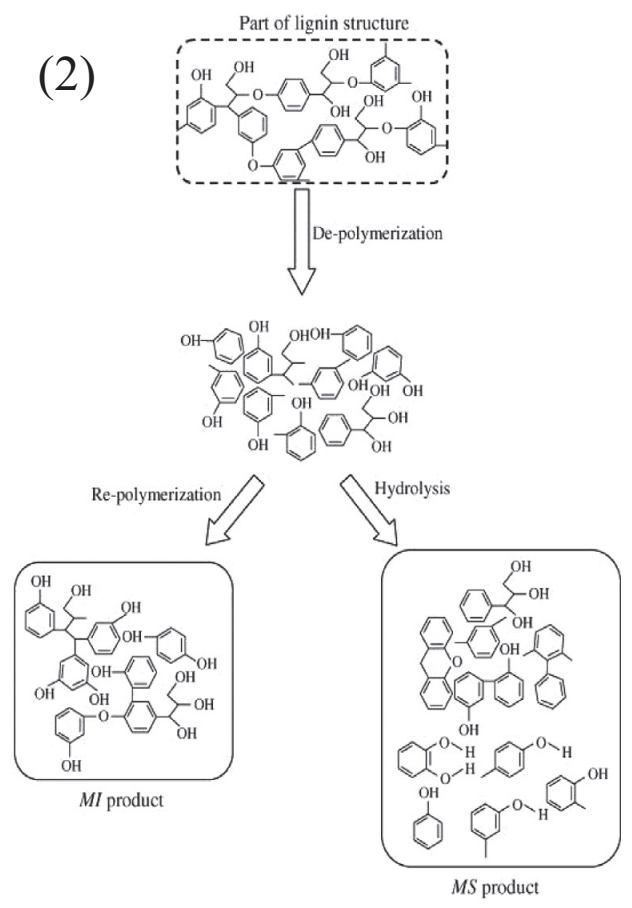

(3)
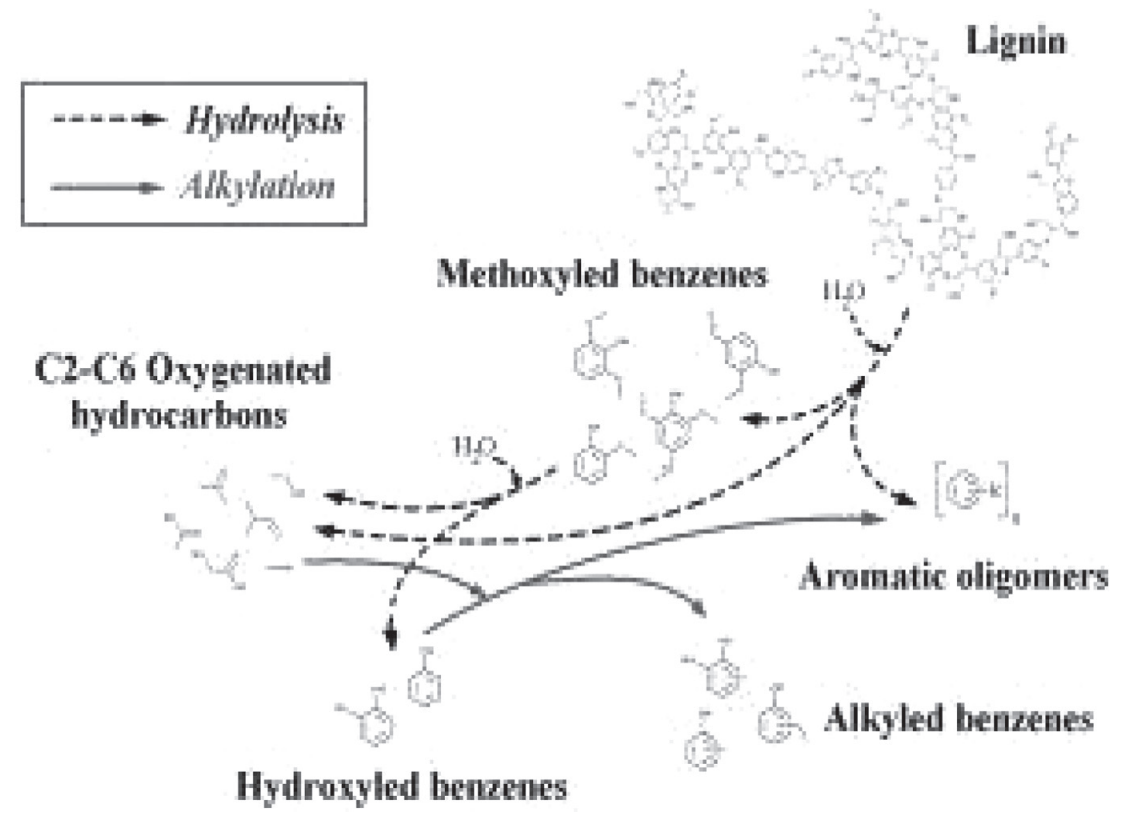

Fig. 6. Reaction schemes for hydrothermal conversion of lignin (Reprinted with permission from [79], @ 2006 American Chemical Society, and from [148,149] with permission from Elsevier).

liquefaction, leading to even more complex reactions schemes. The following section summarizes therefore the main interactions between model compounds of the biomass.

\subsubsection{Mixtures}

Bio oil yields generally increase when real resources are used instead of model compounds, due to interactions phenomena. While a great research effort has been made with pure model compounds, few studies are reported about mixtures of model molecules of various natures.
The majority of the studies dealing with mixtures of model com pounds focuses on the interactions between proteins and sugars, which interact following a complex reaction mechanism known as the Maillard reaction. This reaction is a three step mechanism which produces nitrogen heterocycles and heavy nitrogenous polymers known as melanoidins. Melanoidins were identified after hydro thermal conversion of a binary mixture of glucose and glycine in several studies, and are responsible for the formation of a brown stable emulsion instead of a bio oil [207 209]. The formation of melanoidins is therefore a critical issue for hydrothermal liquefaction. 


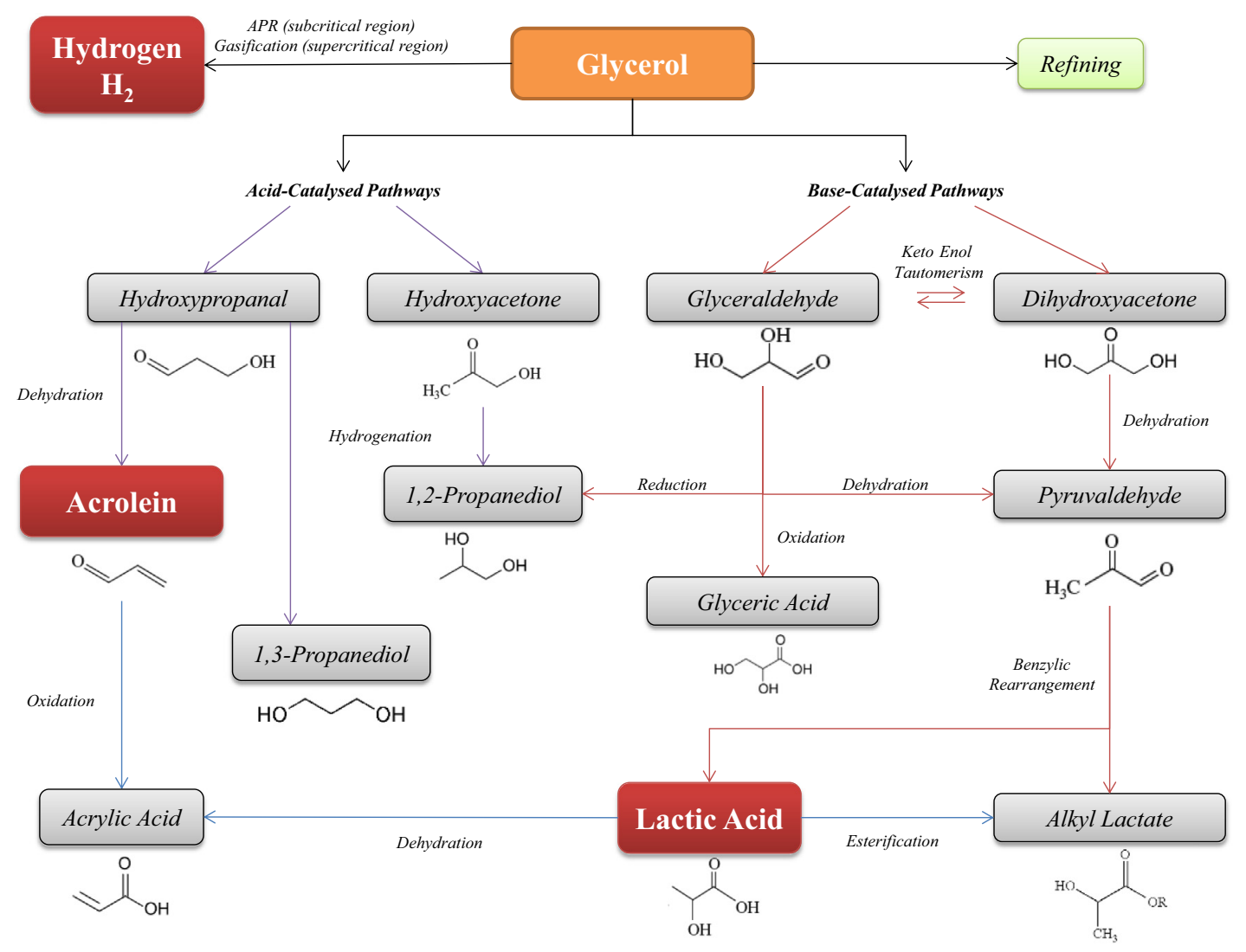

Fig. 7. Products from hydrothermal conversion of glycerol [203].

Above $200^{\circ} \mathrm{C}$, melanoidins decompose to produce gas, insoluble char, ammonia and water soluble organics [207]. At temperatures higher than $250^{\circ} \mathrm{C}$, nitrogenous compounds such as pyridine and pyrazines are formed, contributing to the bio oil yield. In addition, they could inhibit the reactions leading to char and gas by producing free radical scavengers in the reaction medium [210]. Therefore, the Maillard reaction is detrimental to the bio oil yield at temperatures under $250^{\circ} \mathrm{C}$ by forming heavy insoluble nitrogenous polymers. However, it contributes to the bio oil yield above $250{ }^{\circ} \mathrm{C}$, increasing at the same time the nitrogen content in the bio oil. Recently, Teri et al. [97] stu died mixtures of model compounds for hydrothermal treatment of lipids, proteins and polysaccharides. They concluded that interactions between proteins and polysaccharides greatly influenced the bio oil yield, and used a mass averaged model of individual model com pounds to predict with good accuracy yields for ternary mixtures.

Few studies focus on other interactions than those between polysaccharides and proteins. In subcritical water, fatty acids and amines interact to form long chain amides, therefore contributing to increasing the bio oil yield [86,202,211]. Some papers also report interactions between lignin and cellulosic fibres, which decrease the formation of gas. In fact, the degradation products of cellulose and hemicelluloses can act as hydrogen donors and inhibit free radical reactions leading to the formation of gas [212 214]. Finally, interactions between polysaccharides and lipids could increase the bio oil yield and decrease the amount of char: carboxylic acids produced by hydrothermal conversion of cellulose could enhance the formation of long chain aliphatic compounds found in the bio oil [202].

Studies on hydrothermal conversion of model compounds of the biomass evidenced that the first and common reaction of biopolymers in subcritical water is hydrolysis, releasing oligomers and monomers in the reaction medium. Monosaccharides are obtained from cellulosic polymers, methoxyphenol derivatives from lignin, amino acids from proteins, fatty acids and glycerol from triglycerides. Those monomers are not stable in the condi tions of hydrothermal liquefaction and degrade subsequently fol lowing many degradation pathways, leading to the diversification of reaction products. Fragmentation reactions, such as breaking of C C bonds by retro aldol condensations, are mostly responsible for the formation of light polar molecules found in the aqueous phase. Bio oil formation can result from monomers alone as in the case of fatty acids, or from condensation of light intermediates that generate hydrophobic molecules. Dehydration and decarboxyla tion reactions contribute to reducing the oxygen content of the reaction products, which favours the amount and the quality of the bio oil. Especially, decarboxylation is the main reaction of gas formation in the conditions of hydrothermal liquefaction, and removes oxygen from the products without removing hydrogen. Finally, condensation reactions of light intermediates, furan and phenolic derivatives lead to polymeric char, mainly during HTL of fibre rich resources. Depending on operating conditions, especially temperature, acidity and reaction time, the reactions driven can differ. For instance, high temperatures increase fragmentation reactions, and basic $\mathrm{pH}$ values contribute to reduce the production of char during HTL of fibre rich biomass. Finally, interaction reactions between molecules of different natures can impact positively or negatively the bio oil yield and quality, which can be used for adjusting the composition of the substrate at the inlet of HTL processes. As discussed in this section, hydrothermal con version of model compounds provides useful information about fundamental reaction mechanisms. However, the question of the representativeness towards HTL of real resources also needs to be 
considered, especially for modelling purposes and further imple mentation of the technology at larger scales.

\section{Process development for HTL of food processing residues}

Different categories of experimental HTL reactors have been presented in the literature. As discussed in the previous paragraphs, the most common research tool for studying HTL is the autoclave batch reactor, mainly because it is the easiest to operate. In fact, it does not require technological developments to pump the biomass at the inlet of the process, nor the highly viscous bio oil produced at the outlet. In this configuration, biomass, water and additives are mixed in a closed reactor and heated to the operating temperature. However in batch mode, heating and cooling times can be relatively long depending on the size and weight of the reactor, directly impacting the thermodynamics and kinetics of the reactions and thus the obtained products. An alternative type of reactor is a semi continuous system in which a heated tube containing biomass in a basket is put in contact with pressurised hot water. Reaction pro ducts are removed as water flows through the tube and are recovered downstream. This system retains most of the char in the reactor. Finally, continuous reactors also exist. In this configuration, a slurry of biomass and water flows through the reactor and the products are separated downstream. While lab scale studies showed the feasibility of hydrothermal liquefaction applied to food processing residues, and allowed the identification of the main influencing parameters, very few industrial reactors have been effectively built, even though some are described in patents.

\subsection{Pilot and semi industrial scale: past and recent developments}

Several HTL processes have been developed in the past. Table 3 shows the operating conditions and treatment capacities for the processes discussed in this section.

The first developments in the field of hydrothermal liquefaction of biomass date back to the 1970s 1980s, under the denomination of direct biomass liquefaction. Early research efforts were made both in the USA and in the Netherlands. In the USA, two processes were developed for converting wood chips into oil: the BOM (Bureau Of Mines) process also known as the PERC (Pittsburgh Energy Research Centre) process, and the LBL (Lawrence Berkeley Laboratory) Process. Many details on these processes can be found in documents written by Douglas C. Elliott $[217,218]$. As illustrated by the block diagrams in Fig. 8 and Fig. 9, the BOM and the LBL processes have only slight differences. In fact, they can be con sidered as two versions of the same process: the main differences concern pre treatment and post conversion steps.

The original BOM process involves drying and grinding the biomass prior to mixing it with anthracene oil. The LBL process does not require any drying nor grinding the biomass: it uses an acid hydrolysis step to turn the biomass into a pumpable water slurry. In addition, the LBL process does not mix the biomass slurry with anthracene oil. In both processes, the slurry is then pumped towards the reactor to be converted in presence of $\mathrm{CO} / \mathrm{H}_{2}$ as well as an aqueous solution of sodium carbonate catalyst. Conversion products are then separated. Unlike the BOM process, the LBL process uses a gravity separator to recover the aqueous phase. Oil can then be separated from heavy products by vacuum distillation. While the LBL process does not require recycling the oil produced, it is necessary to recycle the aqueous phase, especially to recover the catalyst and dissolved organic matter.

The first European developments in the field of hydrothermal liquefaction of biomass also date back to the 1980s, with research efforts made by the Dutch company Shell on the HTU process (Hydrothermal Upgrading). Wet agricultural wastes such as
Table 3

Typical operating conditions for hydrothermal liquefaction processes at the pilot scale $[26,69,101,215,216]$.

\begin{tabular}{lllll}
\hline Process & $\boldsymbol{T}\left({ }^{\circ} \mathbf{C}\right)$ & $\boldsymbol{P}(\mathbf{M P a})$ & $\boldsymbol{t}(\mathbf{m i n})$ & Plant scale \\
\hline BOM (PERC) & $300-370$ & 20 & $10-30$ & $18 \mathrm{~kg}$ wood $/ \mathrm{h}$ \\
LBL & $330-360$ & $10-24$ & $10-60$ & $18 \mathrm{~kg}$ wood $/ \mathrm{h}$ \\
HTU & $300-360$ & $10-18$ & $5-20$ & $100 \mathrm{~kg} / \mathrm{h}$ of wet biomass \\
CatLiq & 350 & 25 & $1-15$ & $20 \mathrm{~L} / \mathrm{h}$ \\
TDP & $200-300$ & 4 & 15 & 250 tons of waste $/$ day \\
TCC & $275-350$ & $55-18$ & 15 & 40 barrels of oil/day \\
\hline
\end{tabular}

beetroot pulp were subjected to hydrothermal liquefaction in a pilot plant able to treat $100 \mathrm{~kg}$ of wet biomass per hour. A block diagram of the process is shown in Fig. 10. The company Nextfuels, subsidiary of Enagra Inc., is currently developing a commercial scale unit in Asia for producing 1000 barrels of oil equivalent per day by hydrothermal liquefaction of palm oil wastes [219].

Another process is the CatLiq process developed by the Danish company SCF Technologies A/S, for treating various sources of biomass such as sewage sludge, algae and manure. A $2030 \mathrm{~L} / \mathrm{h}$ pilot plant facility was developed for producing a bio oil with a yield of $3035 \mathrm{wt} \%$, and an energy recovery of $7075 \mathrm{wt} \%$ [221]. A simplified flow diagram is reported in Fig. 11. The CatLiq process is quite different from other HTL processes, as it combines a homo geneous alkali catalyst to solubilise the majority of the carbon in aqueous phase, which is further refined using a heterogeneous catalyst $\left(\mathrm{ZrO}_{2}\right)$ to produce bio oil. In 2011, the Turkish company Altaca Environmental Technologies and Energy bought the tech nology with the idea of developing a commercial scale unit for treating $200 \mathrm{t}$ per day of dairy wastes [222]. Experience on the CatLiq process led the developers to found the company Steeper Energy, which currently runs a pilot plant in Aalborg University (Denmark) and is developing commercial plants up to 5000 bar rels per day [243].

In the early 2000s, the company Changing World Technologies developed the TDP process (Thermal Depolymerisation) at a commercial scale for the hydrothermal conversion of $250 \mathrm{t}$ per day of meat processing wastes, yielding 500 barrels of bio oil per day [66,67]. Fig. 12 shows the block diagram of the TDP process. Two conversion stages allow the process to produce readily valu able products: the solid minerals and nitrogen rich aqueous phase can be sold as bio based fertilizers, the fuel gas and char can be burnt directly to meet the heating needs of the process or sold as fuels. The second reactor heats the liquid phase up to $500{ }^{\circ} \mathrm{C}$ to produce $C_{15}$ to $C_{20}$ hydrocarbons which can be further upgraded to transportation fuels. The commercial plant operated from 2004 to 2009, before Changing World Technologies went bankrupt due to poor profitability as well as odour related complaints. In 2013, the Canadian firm Ridgeline Energy Services bought the commercial scale plant and added a wastewater treatment unit to the process [223].

The TCC process (Thermochemical Conversion) was developed by the University of Illinois (USA) and a pilot plant for performing HTL of swine manure was created in 2005 , to produce 40 barrels of bio oil per day $[69,224]$. The particular feature of this process is the injection of $\mathrm{CO}$ in the reactor. The company Worldwide Bioe nergy commercialised the process, and Fig. 13 shows a block dia gram of the process.

Other processes for liquefying wet biomass have been devel oped in the past, as Toor et al. [26] discussed in a previous review. Yet, they do not all correspond to a strict definition of a hydro thermal process, for instance because they only use a hydrogen atmosphere without water as the DoS process developed in Hamburg [216]. Finally, the STORS processes (Sludge To Oil Reac tor Systems) runs under the principle of a high pressure 


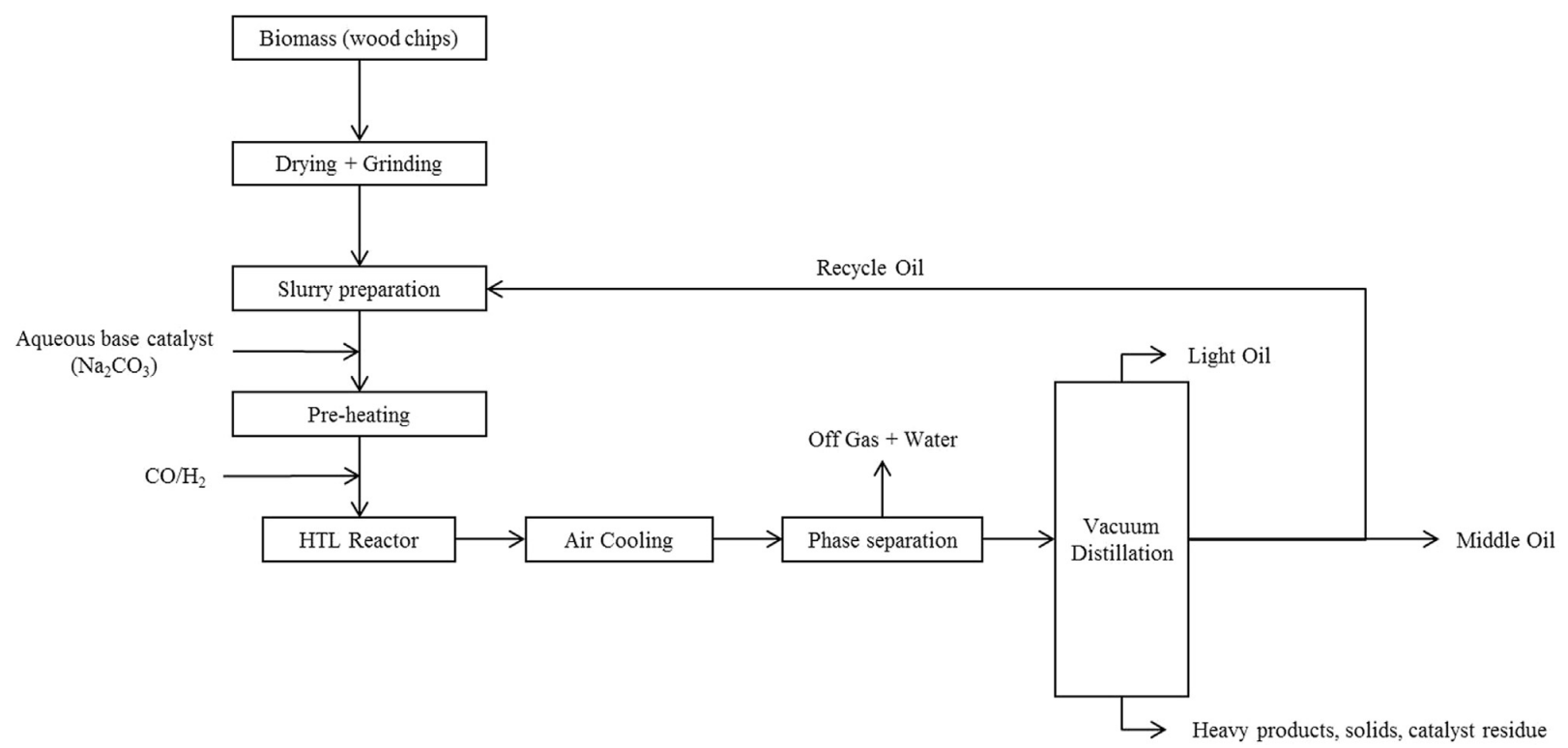

Fig. 8. Block diagram of the BOM process (adapted from [218]).

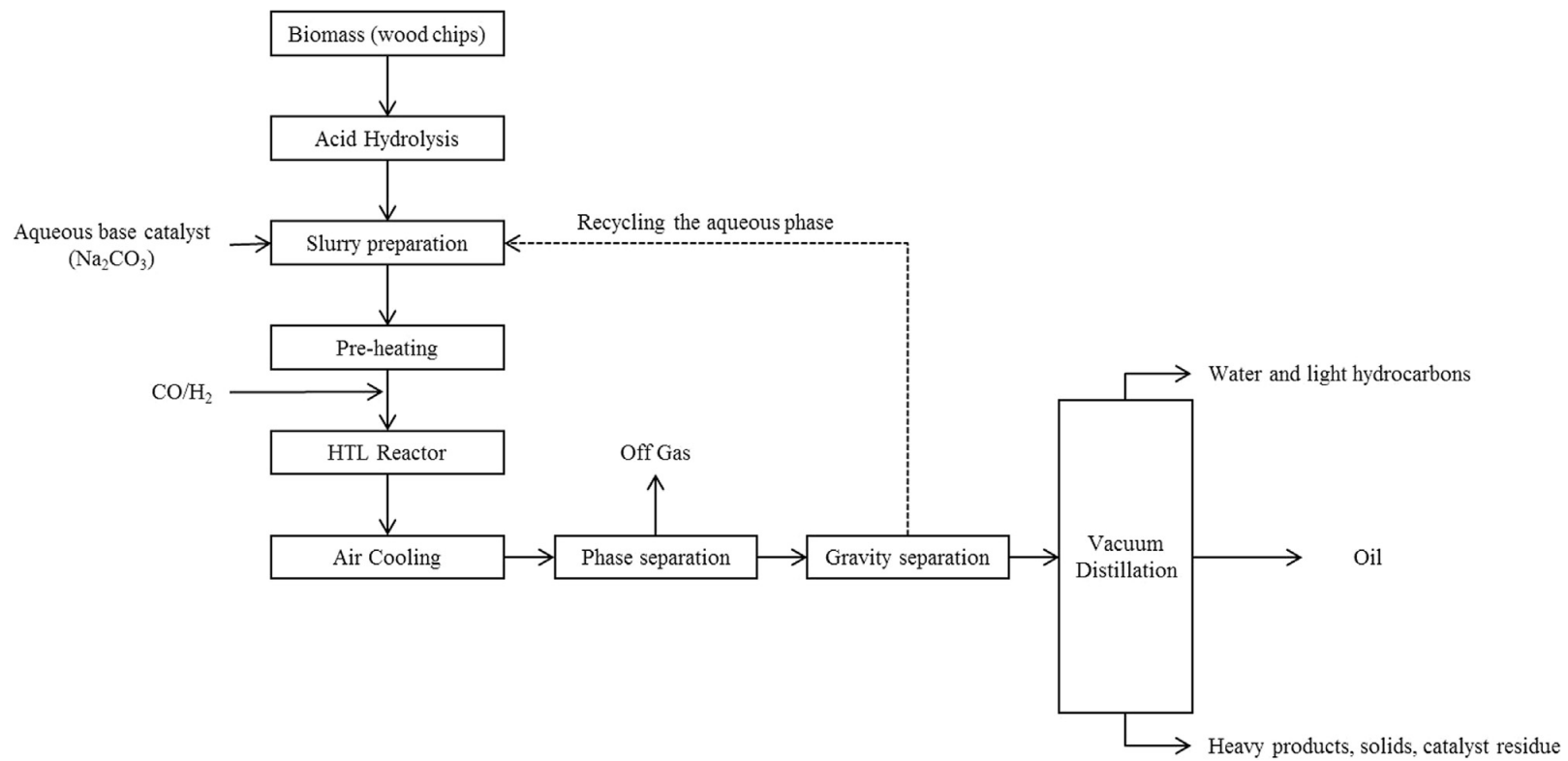

Fig. 9. Block diagram of the LBL process (adapted from [218]).

distillation column removing continuously gases, volatile organics and an aqueous phase and recovering the oil by solvent extraction. STORS processes started developing in the USA in the 1980s [225], and in Japan in the 1990s [226]. Today, a STORS process is com mercialised by the company ThermoEnergy under the name of ThermoFuel process [227].

Hydrothermal liquefaction of food processing residues has been effectively demonstrated at the pilot scale by the means of several processes developed as soon as the 1980s. They were designed to treat many different substrates, from fruit and vegetable processing residues to dairy and meat processing wastes. Many of these pro cesses ceased operation, due to different reasons. First of all, most of the units faced critical technological issues, due to the harsh oper ating conditions of hydrothermal liquefaction which directly impact the lifetime of the units. Particularly, pumping and feeding solid suspensions at such conditions can lead to major plugging issues, even more when the amount of char produced is high. The eco nomic viability of many of the processes described above was also a critical issue. In fact, the use of relatively harsh conditions impor tantly impacts the capital and operating costs. In addition, the variations in the price of fossil fuels along the years led to scattered research efforts, delaying the development of commercial scale units. Even though some of the processes described in the present section are now being developed for larger capacities, there are still many questions to answer before scaling up hydrothermal lique faction at the commercial scale. Particularly, pre treatment meth ods adapted to the substrates, as well as development of efficient and reliable equipment and process integration through valorisa tion of every by product have to be addressed. 


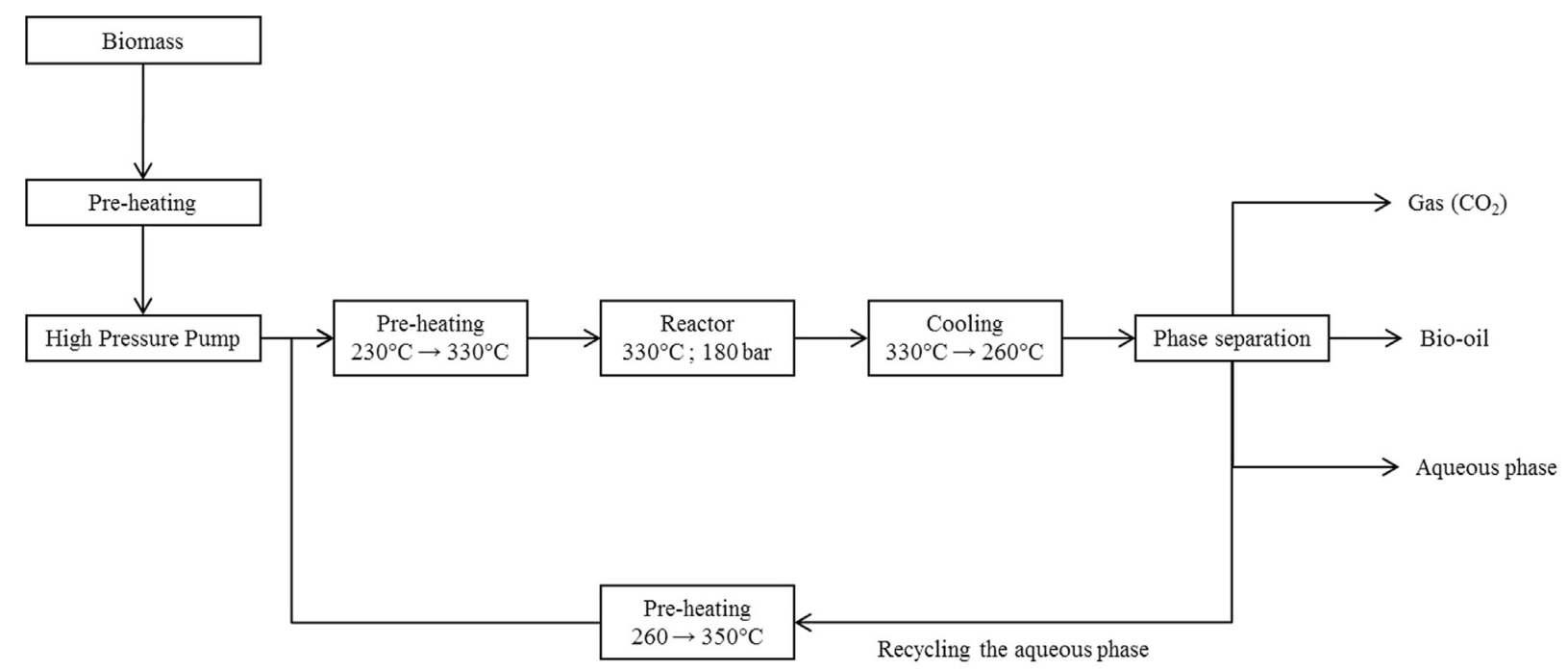

Fig. 10. Block diagram of the HTU process (adapted from [220]).

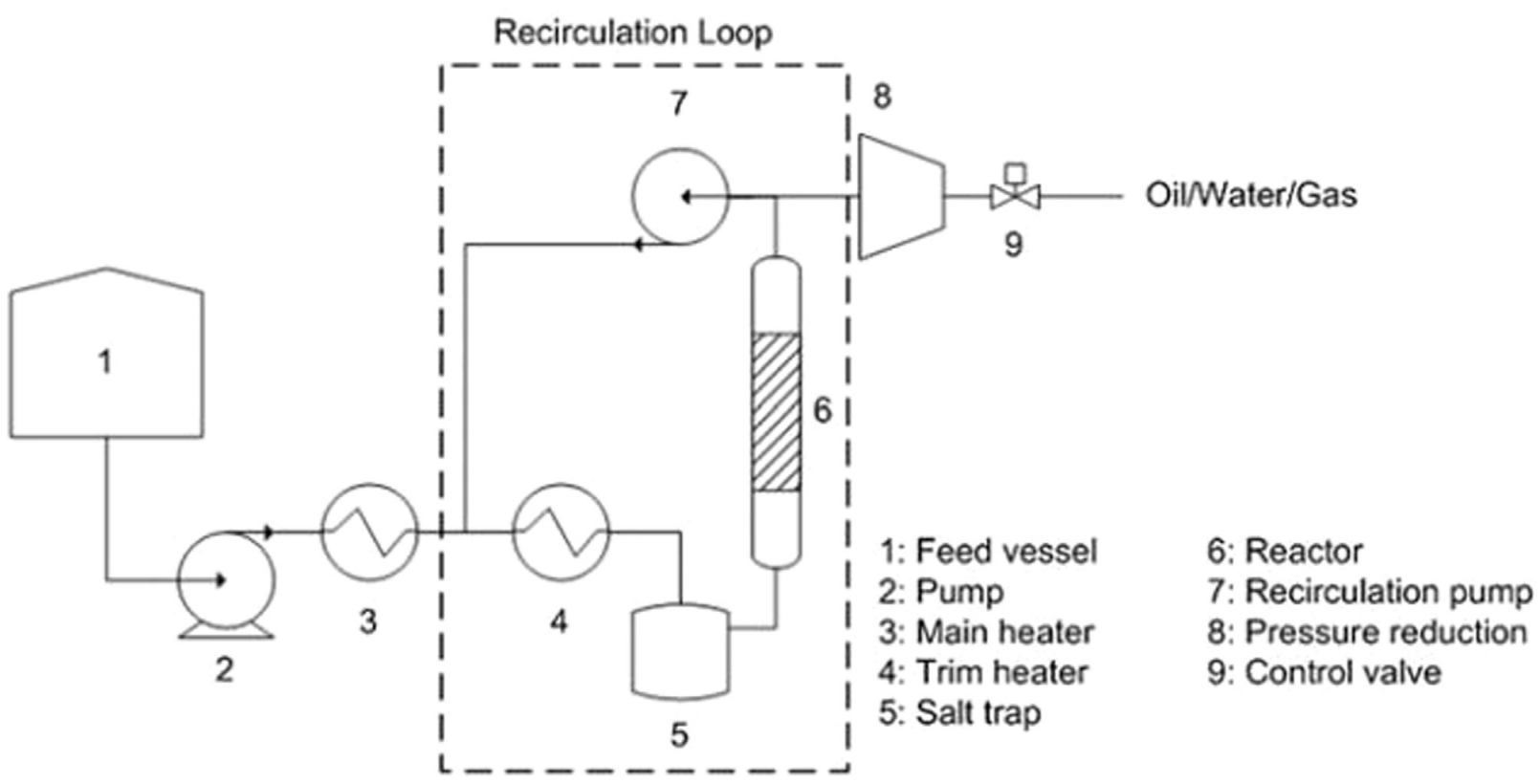

Fig. 11. Simplified flow diagram of the CatLiq process (Reprinted from [221], with permission from Elsevier).

4.2. Future challenges for process development at commercial scales

This section discusses general challenges linked to the devel opment of HTL processes at commercial scales, and does not focus specifically on food processing residues. In fact, irrespective of the substrates, scaling up hydrothermal liquefaction at the commercial scale is facing equipment related issues, as well as economic and environmental issues relative to the handling of the aqueous effluents and upgrading of bio oils.

\subsubsection{Technological issues}

Hydrothermal liquefaction occurs at relatively high pressures and temperatures. These harsh conditions are responsible for operating issues impacting the investment and lifetime of the units, namely high pressure pumping for feeding the biomass, high energy consumption for maintaining high temperatures and corrosion.
As underlined in a recent review by Elliott et al. [31], higher slurry concentrations and higher operating pressures are the key parameters to reduce capital costs. In fact, they would lower capital costs by allowing the use of smaller processing units. However, they lead to increased difficulties for pumping and call for innovative and reliable technologies for high pressure feeding of biomass slurries at high concentration of solids. In fact, pump ing and feeding solid suspensions at such conditions can lead to major plugging issues, even more when the amount of char pro duced is high. Therefore, finding efficient pumping systems for the conditions of HTL is one of the technological challenges for the development of the process at industrial scales. Even though commercial scale systems do exist for other applications, they only have been demonstrated in bench scale studies for HTL [31]. In addition, pre treatment strategies could be found to avoid plugging: preparation of biomass slurries with sufficiently low granularity by a cost effective wet grinding step, or chemical 


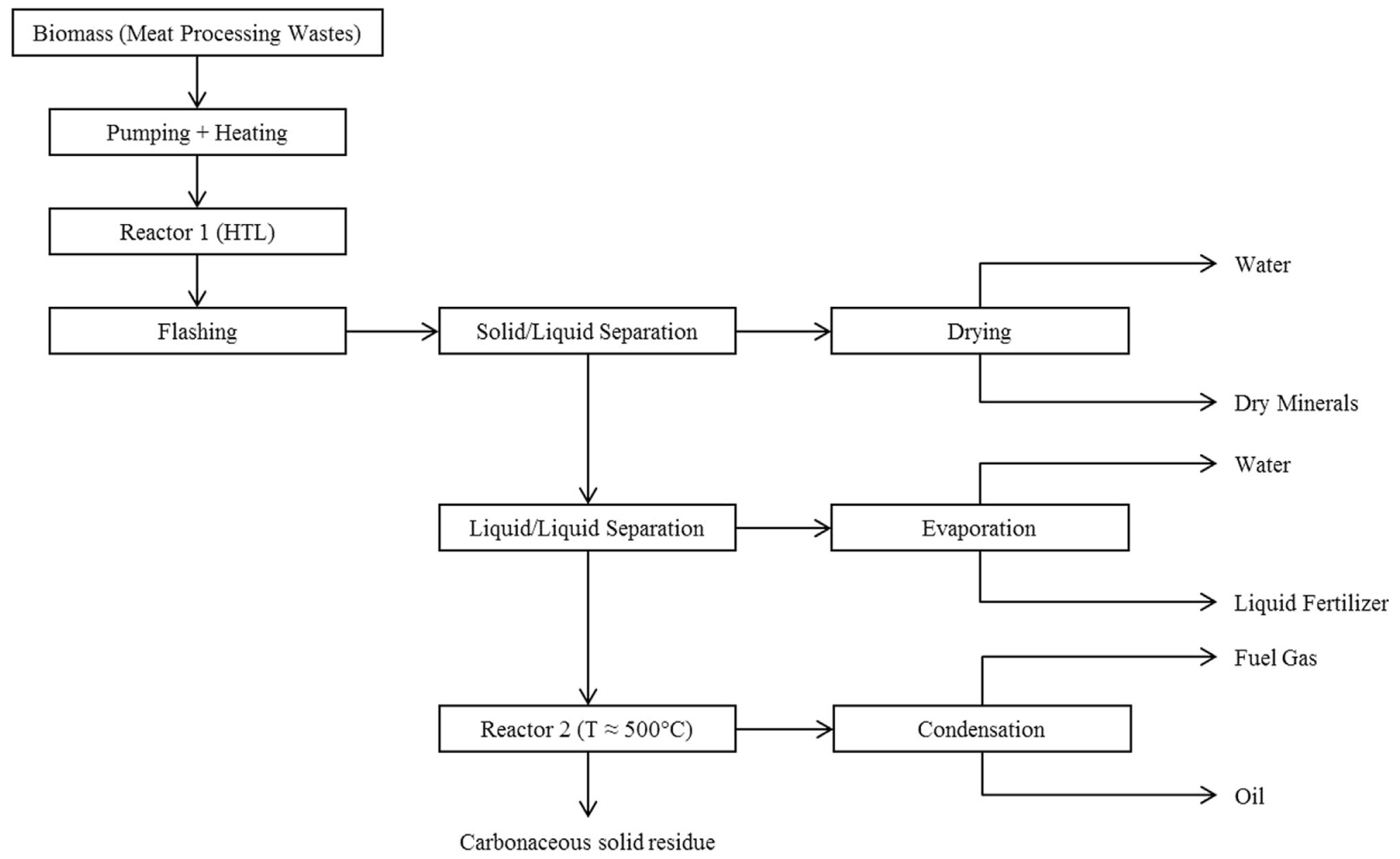

Fig. 12. Block diagram of the TDP process (Adapted with permission from [67]).

treatment such as acid hydrolysis used in the LBL process. Addi tives could also be used to limit the formation of char during the conversion step.

In addition to plugging issues, corrosion of pipes and conver sion units also has to be taken into account when designing hydrothermal processes. This is especially true when dealing with ash rich resources in near or supercritical conditions. For instance, high chlorine content in the raw material could cause stress cor rosion, leading to local and deep cracking into the material, therefore reducing the lifetime of the installation. Consequently, the construction material of the reactor has to be mechanically and chemically resistant. Very little experience on material corrosion in the field of hydrothermal liquefaction is available, mainly due to short operation times of the pilot scale units. However, corrosion is likely to be highly dependent on the composition of each feedstock, underlining the need for systematic studies to evaluate the potential for corrosion. A recent paper by Mørup et al. [228 provides detailed and valuable information on many technological issues encountered in the development of a pilot scale HTL unit, especially regarding feeding, heating and recovery of products.

\subsubsection{Valorisation of the aqueous effluent}

Due to the use of water as the reaction medium, hydrothermal liquefaction generates contaminated aqueous effluents in large amounts, especially when additional water is needed to meet the process input specifications. Most processes recycle water, but also maintain constant water to biomass ratio in the reactor. Conse quently, all water entering the process with the biomass must be purged, leading to the generation of a certain amount of water contaminated with dissolved organics. This is a real challenge for the development of HTL processes at a large scale, because treat ment of this aqueous effluent in a sewage plant is expensive and impairs the financial advantages of HTL. It is therefore necessary to set up ways of recovering or recycling the organic load and nutri ents contained in the wastewaters. This is a crucial point to consider for the economics of the process, and several solutions have been suggested regarding the handling of the aqueous effluent.

The use of the contaminated aqueous stream in a post conversion step received a great deal of attention, especially for algae cultivation purposes. The idea is to treat the aqueous phase by Catalytic Hydrothermal Gasification (CHG), prior to recycling a relatively clean and nutrient rich aqueous phase as a growth medium for microbial or algae cultivation. Recycling of nutrients is a key parameter for the development of biofuel production systems based on algae feedstock, due to the high production and envir onmental costs associated with nutrient production. Depending on the operating conditions, $\mathrm{CHG}$ produces either $\mathrm{CH}_{4}$ used as fuel gas or $\mathrm{H}_{2}$ that can be used for hydrogenation of the bio oil. Carbon dioxide as well as a clean nutrient rich aqueous phase are also produced by CHG. Recycling nutrients to the algae growth facilities along with fuel gas production from water soluble organics was effectively demonstrated for microalgal and macroalgal systems $[229,230]$. Especially, CHG allows the recovery of phosphorus and nitrogen (recovered as dissolved ammonia) in the aqueous phase. In addition, the CHG post conversion step can obviously be extended to a broad range of feedstocks, including wastes.

Some studies report the direct recycling of the aqueous phase loaded with organic compounds towards algae cultivation facilities without CHG. In that case, dilution of the recycled effluents is necessary to avoid growth inhibition due to the presence of inhi bitors such as phenols. However, studies showed that some algae are able to adapt and grow using the organic carbon in the aqu eous phase [231,232].

Another way of handling the residual carbon contained in the aqueous stream generated at the outlet of the reactor is the direct recycling of the aqueous phase at the inlet of the conversion unit. This is especially true for biomass requiring dilution in the lique faction reactor. For instance, Zhu et al. [233] reported an increase of the bio oil yield and heating value after recycling the aqueous phase produced by $\mathrm{HTL}$ of barley straw at $300{ }^{\circ} \mathrm{C}$. Solid residues 


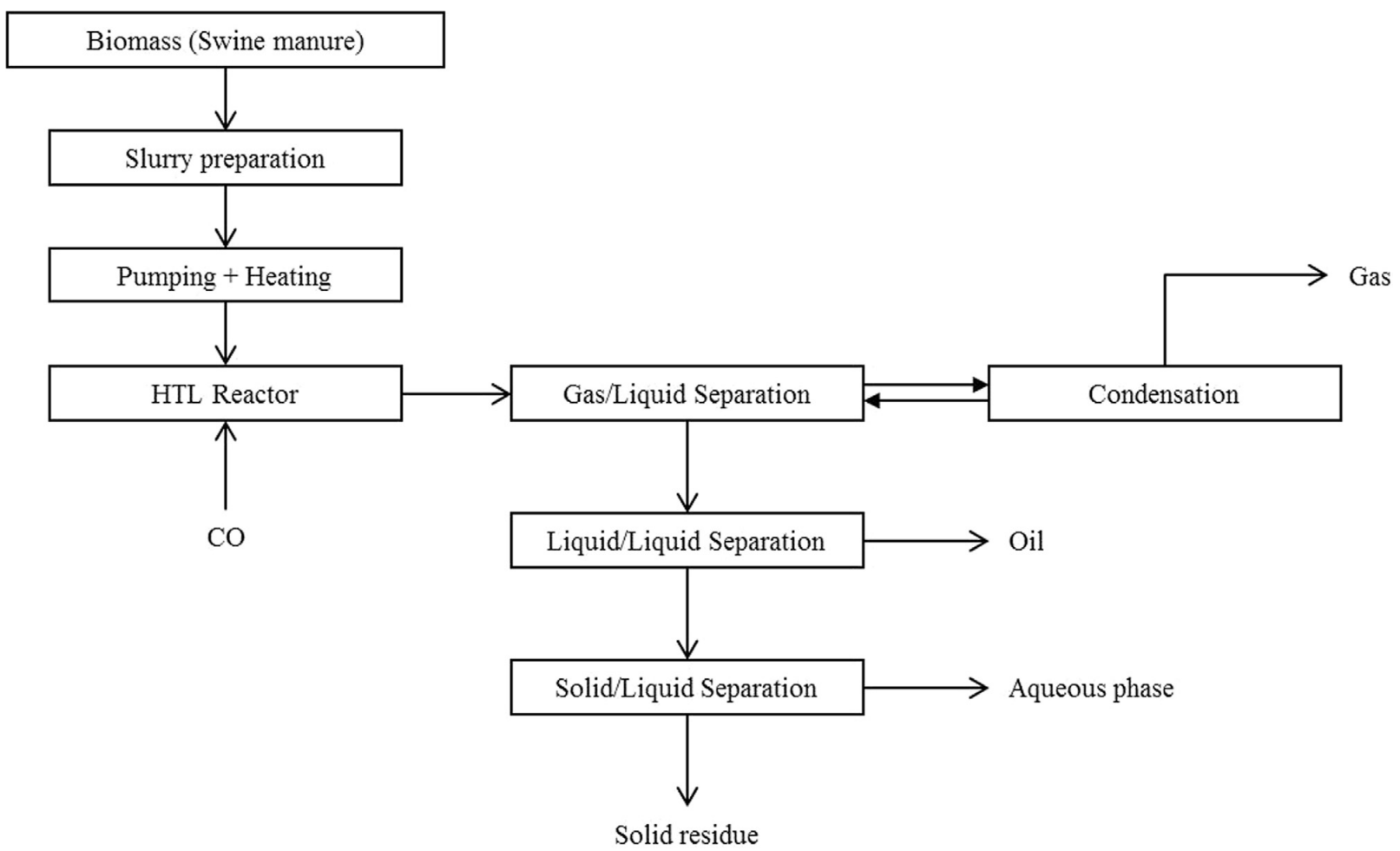

Fig. 13. Block diagram of the TCC process (Adapted from [69]. Used with permission.).

were at the same time obtained in higher amounts and with higher heating values. As well, Ramos Tercero et al. [234] recently reported nearly a threefold increase of the bio oil yield from 14.3 wt\% to $42.2 \mathrm{wt} \%$ after 6 recycles of the aqueous phase during HTL of the microalgae $C$. Vulgaris at $240{ }^{\circ} \mathrm{C}, 30$ min residence time.

Anaerobic digestion has recently received some interest to treat aqueous streams loaded with residual carbon after hydrothermal processing of biomass [235,236]. For instance, Wirth and Mumme [235] reported a good degradability of COD and TOC, respectively up to $75 \%$ and $54 \%$, by anaerobic digestion of an aqueous effluent generated by hydrothermal carbonisation of corn silage.

\subsubsection{Upgrading of the bio oil}

Due to their high energy content, associated with relatively low nitrogen and sulphur contents, bio oils produced by HTL of wet bio mass can be used as an alternative to heavy fuel oil without further processing. They are also considered as promising alternative to transportation fuels. However, they still contain significantly more heteroatoms than traditional fuels such as gasoline and kerosene. The water content of bio oils is also an issue, not only from an energy perspective but because it may cause corrosion problems and favour microbial growth in long term storages. Bio oils have therefore to be upgraded before any use as engine fuels, due to their high oxygen content, high viscosity and lower energy content compared to tradi tional fuels. Efficient upgrading of bio oils to a readily usable and marketable hydrocarbon fuel is therefore an intense research area. Two ways of upgrading HTL bio oils have been considered, either by using analogous catalysts and operating conditions as in the petro leum catalytic hydrotreatment, or by upgrading the bio oils in hydrothermal conditions.

HTL bio oils can be upgraded by using well known petroleum catalytic hydrotreatment: heterogeneous catalysts such as sup ported metal catalysts (e.g CoMo, NiMo, Pt, Pd or Ru, mostly supported on alumina) are used in the hydrogenation process, as well as temperatures up to $400^{\circ} \mathrm{C}$ and hydrogen pressures near
$20 \mathrm{MPa}$. The main reactions of interest are hydrodeoxygenation, hydrodenitrogenation, and hydrodesulfurization. Hydrocracking, which is a catalytic process used to increase the yield of hydrogen rich fuel products from heavy hydrocarbons, can also be part of the upgrading step [237].

Some studies also report the upgrading of HTL bio oils in hydrothermal conditions. Zeolites [238] and supported metal catalysts $[200,239,240]$ are examples of catalysts used to remove oxygen from the bio oils. Upgrading HTL bio oils has been demonstrated first at the lab scale, using either bio oils produced by HTL of real biomasses such as microalgae [241], or model compounds such as pyridine [242] or soy oil [241]. All studies report an efficient elimination of the oxygen content, along with very low levels of nitrogen and sulphur.

The main processing challenges encountered during the hydrotreatment of HTL bio oils are relative to the high viscosity of the oils, as well as catalyst activity reduction. In fact, biomass derived compounds can deposit over the active catalyst surfaces and reduce their efficiency as well as their lifetime. Although lab scale studies showed the feasibility of such treatment of bio oils produced by HTL of biomass, questions still remain regarding the long term operation of such processes. The question of catalyst activity is particularly important, as long as catalyst activities are needed to ensure the economic viability of the upgrading step.

\section{Conclusion}

The upcoming shortage of fossil fuels makes necessary the search for alternative solutions such as bio based fuels produced from renewable resources. At the same time, the amount of wet organic wastes generated by the food industries is increasing each year, mainly due to population growth worldwide and industrialisation of the food industry. These wastes are currently valorised for low value applications that sometimes lead to 
environmental and sanitary problems. The huge amount of wet organic wastes must be seen as an opportunity for material and energy valorisation. In fact, using resources with low (or even negative) cost may create interesting economic opportunities. Along this paper, we have shown that hydrothermal liquefaction is a particularly suitable process to convert wet food processing residues into renewable liquid fuels, which cost could compete with the actual production cost of transportation fuels from fossil resources. HTL does not require any drying prior to con version and converts biomass into energy dense bio oils. Although HTL is promising in terms of bio oil quantity and quality, issues relative to the prediction of bio oil production from various food wastes and to the use of continuous units are delaying the industrialisation of the technology.

While many studies were conducted in small batch reactors for screening operating parameters on many resources, fundamental mechanisms behind HTL chemistry need further clarification. The complex reaction network, leading to hundreds of different reac tion products, is still badly understood. Even though studies on pure model compounds and simple mixtures allowed the identi fication of the main reaction pathways, fewer studies are reported in the literature regarding the behaviour of complex mixtures of model compounds. This paper has presented the state of the art of these reaction mechanisms, but also that the comprehension of what happens to real biomass is still a long way off. Further work is therefore needed to reach an exhaustive understanding of the reactivity of real resources. The highly complex composition of HTL products represents an analytical challenge that needs to be addressed for improving the comprehension of all mechanisms involved in HTL. In addition, while using model compounds pro vides useful information about fundamental reaction mechanisms, the question of the representativeness towards HTL of real resources also needs to be considered.

Despite the promising results of HTL at laboratory scale, industrial development is slow due to both technical and eco nomic issues. Along the last 40 years, the variations in the price of fossil fuels have led to scattered research efforts, delaying the development of commercial scale units. In addition, operating issues and poor profitability often prevented pilot scale HTL units to run for long time periods. The lack of reliable technologies adapted to the harsh conditions of the process directly impacts both the lifetime and the investment costs of the installations. This calls for technological development of robust high pressure/high temperature technologies. Finally, the economics of HTL also relies on efficient management of the various streams at the outlet of the HTL conversion unit. In particular, HTL bio oils need to be effi ciently upgraded requiring further development of active and specific catalysts. The aqueous stream contaminated with organic compounds has to be valorised to ensure economic viability of the process, either by direct recycling, as fertilizer/culture medium, or as a source of bio based specialty chemicals.

\section{Acknowledgements}

The authors would like to acknowledge financial support from the French Research National Agency ANR (LIQHYD Project) (Grant no. ANR 12 BIME 0003).

\section{References}

[1] IEA. Key world energy statistics. France: International Energy Agency; 2013.

[2] Vardanega R, Prado JM, MAA Meireles. Adding value to agri-food residues by means of supercritical technology. J Supercrit Fluids 2014;96:217-27.
[3] Viganó J, APdF Machado, Martínez J. Sub- and supercritical technology applied to food waste processing. J Supercrit Fluids 2014;96:272-86.

[4] Pham TPT, Kaushik R, Parshetti GK, Mahmood R, Balasubramanian R. Foodwaste-to-energy conversion technologies: current status and future directions. Waste Manag 2015;38:399-408.

[5] Akiya N, Savage PE. Roles of water for chemical reactions in hightemperature water. Chem Rev 2002;102:2725-50.

[6] Weingärtner H, Franck EU. Supercritical water as a solvent. Angew Chem Int Ed 2005;44:2672-92.

[7] Kruse A, Dinjus E. Hot compressed water as reaction medium and reactant: 2. Degradation reactions. J Supercrit Fluids 2007;41:361-79.

[8] Kruse A, Dinjus E. Hot compressed water as reaction medium and reactant: properties and synthesis reactions. J Supercrit Fluids 2007;39:362-80.

[9] Yu Y, Lou X, Wu H. Some recent advances in hydrolysis of biomass in hotcompressed water and its comparisons with other hydrolysis methods. Energy Fuels 2007;22:46-60.

[10] Brunner G. Near critical and supercritical water. Part I. Hydrolytic and hydrothermal processes. J Supercrit Fluids 2009;47:373-81.

[11] Savage PE. A perspective on catalysis in sub- and supercritical water. J Supercrit Fluids 2009;47:407-14

[12] Möller M, Nilges P, Harnisch F, Schröder U. Subcritical water as reaction environment: fundamentals of hydrothermal biomass transformation. ChemSusChem 2011;4:566-79.

[13] Jin F, Enomoto H. Rapid and highly selective conversion of biomass into value-added products in hydrothermal conditions: chemistry of acid/basecatalysed and oxidation reactions. Energy Environ Sci 2011;4:382-97.

[14] Simsek Kus N. Organic reactions in subcritical and supercritical water. Tetrahedron 2012;68:949-58.

[15] Kang S, Li X, Fan J, Chang J. Hydrothermal conversion of lignin: a review. Renew Sustain Energy Rev 2013;27:546-58.

[16] Kruse A, Dahmen N. Water - a magic solvent for biomass conversion. J Supercrit Fluids 2015;96:36-45.

[17] Peterson AA, Vogel F, Lachance RP, Froling M, Antal JMJ, Tester JW. Thermochemical biofuel production in hydrothermal media: a review of sub- and supercritical water technologies. Energy Environ Sci 2008;1:32-65.

[18] Biller P, Ross AB. Hydrothermal processing of algal biomass for the production of biofuels and chemicals. Biofuels 2012;3:603-23.

[19] Kruse A, Funke A, Titirici M-M. Hydrothermal conversion of biomass to fuels and energetic materials. Curr Opin Chem Biol 2013;17:515-21.

[20] Pavlovič I, Knez Ž, Škerget M. Hydrothermal reactions of agricultural and food processing wastes in sub- and supercritical water: a review of fundamentals, mechanisms, and state of research. J Agric Food Chem 2013;61:8003-25.

[21] Yeh TM, Dickinson JG, Franck A, Linic S, Thompson LT, Savage PE. Hydrothermal catalytic production of fuels and chemicals from aquatic biomass. J Chem Technol Biotechnol 2013;88:13-24.

[22] Ruiz HA, Rodríguez-Jasso RM, Fernandes BD, Vicente AA, Teixeira JA. Hydrothermal processing, as an alternative for upgrading agriculture residues and marine biomass according to the biorefinery concept: a review. Renew Sustain Energy Rev 2013;21:35-51.

[23] Tekin K, Karagöz S, Bektaș S. A review of hydrothermal biomass processing. Renew Sustain Energy Rev 2014:40:673-87.

[24] Knez Ž, Markočič E, Hrnčič MK, Ravber M, Škerget M. High pressure water reforming of biomass for energy and chemicals: a short review. J Supercrit Fluids 2015;96:46-52.

[25] Patil V, Tran K-Q, Giselrød HR. Towards sustainable production of biofuels from microalgae. Int J Mol Sci 2008;9:1188.

[26] Toor SS, Rosendahl L, Rudolf A. Hydrothermal liquefaction of biomass: a review of subcritical water technologies. Energy 2011;36:2328-42.

[27] Akhtar J, Amin NAS. A review on process conditions for optimum bio-oil yield in hydrothermal liquefaction of biomass. Renew Sustain Energy Rev 2011;15:1615-24.

[28] Tekin K, Karagöz S. Non-catalytic and catalytic hydrothermal liquefaction of biomass. Res Chem Intermed 2013;39:485-98.

[29] López Barreiro D, Prins W, Ronsse F, Brilman W. Hydrothermal liquefaction (HTL) of microalgae for biofuel production: State of the art review and future prospects. Biomass Bioenergy 2013;53:113-27.

[30] Tian C, Li B, Liu Z, Zhang Y, Lu H. Hydrothermal liquefaction for algal biorefinery: a critical review. Renew Sustain Energy Rev 2014;38:933-50.

[31] Elliott DC, Biller P, Ross AB, Schmidt AJ, Jones SB. Hydrothermal liquefaction of biomass: developments from batch to continuous process. Bioresour Technol 2015;178:147-56.

[32] Xiu S, Shahbazi A. Bio-oil production and upgrading research: a review. Renew Sustain Energy Rev 2012;16:4406-14.

[33] Chow MC, Jackson WR, Chaffee AL, Marshall M. Thermal treatment of algae for production of biofuel. Energy Fuels 2013:27:1926-50.

[34] Marcilla A, Catalá L, García-Quesada JC, Valdés FJ, Hernández MR. A review of thermochemical conversion of microalgae. Renew Sustain Energy Rev 2013;27:11-9.

[35] Milledge J, Smith B, Dyer P, Harvey P. Macroalgae-derived biofuel: a review of methods of energy extraction from seaweed biomass. Energies 2014; 7:7194.

[36] Chen H, Zhou D, Luo G, Zhang S, Chen J. Macroalgae for biofuels production: progress and perspectives. Renew Sustain Energy Rev 2015;47:427-37.

[37] Chen W-H, Lin B-J, Huang M-Y, Chang J-S. Thermochemical conversion of microalgal biomass into biofuels: a review. Bioresour Technol 2015;184:314-27. 
[38] Chen Y, Wu Y, Hua D, Li C, Harold MP, Wang J, et al. Thermochemical conversion of low-lipid microalgae for the production of liquid fuels: challenges and opportunities. RSC Adv 2015;5:18673-701.

[39] Girotto F, Alibardi L, Cossu R. Food waste generation and industrial uses: a review. Waste Management.

40] FAO. Food wastage footprint: Impacts on natural resources; 2013

[41] FAO. Global initiative on food loss and waste reduction; 2014.

[42] European Comission. Final Report-Preparatory Study on Food Waste across EU27. In: Service BI, editor. Paris; 2010.

[43] Kang S, Li B, Chang J, Fan J. Antioxidant abilities comparison of lignins with their hydrothermal liquefaction products. Bioresources 2011;6:243-52.

[44] Conde E, Moure A, Domínguez H, Parajó JC. Production of antioxidants by non-isothermal autohydrolysis of lignocellulosic wastes. LWT - Food Sci Technol 2011:44:436-42.

[45] Holladay JE, White JF, Bozell JJ, Jonhson D. Top Value-Added Chemicals from Biomass - Volume II - Results of Screening for Potential Candidates from Biorefinery Lignin Richland, WA: Pacific Northwest National Laboratory 2007.

[46] Kang S, Li X, Li B, Fan J, Chang J. Effects of lignins on antioxidant biodiesel production in supercritical methanol. Energy Fuels 2011;25:2746-8.

[47] Rahikainen J, Mikander S, Marjamaa K, Tamminen T, Lappas A, Viikari L, et al. Inhibition of enzymatic hydrolysis by residual lignins from softwood - study of enzyme binding and inactivation on lignin-rich surface. Biotechnol Bioeng 2011;108:2823-34.

[48] Liu H-M, Feng B, Sun R-C. Acid-chlorite pretreatment and liquefaction of cornstalk in hot-compressed water for bio-oil production. J Agric Food Chem 2011:59:10524-31.

[49] Liu Z, Zhang F-S. Effects of various solvents on the liquefaction of biomass to produce fuels and chemical feedstocks. Energy Convers Manag 2008;49:3498-504.

[50] Karagöz S, Bhaskar T, Muto A, Sakata Y. Comparative studies of oil compositions produced from sawdust, rice husk, lignin and cellulose by hydrothermal treatment. Fuel 2005;84:875-84.

[51] Karagöz S, Bhaskar T, Muto A, Sakata Y. Hydrothermal upgrading of biomass: effect of $\mathrm{K} 2 \mathrm{CO} 3$ concentration and biomass/water ratio on products distribution. Bioresour Technol 2006;97:90-8.

[52] Van Rossum G, Zhao W, Castellvi Barnes M, Lange J-P, Kersten SRA. Liquefaction of lignocellulosic biomass: solvent, process parameter, and recycle oil screening. ChemSusChem 2014; 7:253-9.

[53] Qu Y, Wei X, Zhong C. Experimental study on the direct liquefaction of Cunninghamia lanceolata in water. Energy 2003;28:597-606.

[54] Mosteiro-Romero M, Vogel F, Wokaun A. Liquefaction of wood in hot compressed water: Part 1 - experimental results. Chem Eng Sci 2014:109:111-22.

[55] Feng S, Yuan Z, Leitch M, Xu C. Hydrothermal liquefaction of barks into biocrude - effects of species and ash content/composition. Fuel 2014;116:214-20.

[56] Song C, Hu H, Zhu S, Wang G, Chen G. Nonisothermal catalytic liquefaction of corn stalk in subcritical and supercritical water. Energy Fuels 2003;18:90-6.

[57] Akhtar J, Kuang SK, Amin NS. Liquefaction of empty palm fruit bunch (EPFB) in alkaline hot compressed water. Renew Energy 2010;35:1220-7.

[58] Mazaheri H, Lee KT, Bhatia S, Mohamed AR. Sub/supercritical liquefaction of oil palm fruit press fiber for the production of bio-oil: effect of solvents. Bioresour Technol 2010;101:7641-7.

[59] Mazaheri H, Lee KT, Mohamed AR. Influence of temperature on liquid products yield of oil palm shell via subcritical water liquefaction in the presence of alkali catalyst. Fuel Process Technol 2013;110:197-205.

[60] Gan J, Yuan W. Operating condition optimization of corncob hydrothermal conversion for bio-oil production. Appl Energy 2013;103:350-7.

[61] Singh R, Bhaskar T, Dora S, Balagurumurthy B. Catalytic hydrothermal upgradation of wheat husk. Bioresour Technol 2013;149:446-51.

[62] Kumar S, Gupta RB. Biocrude production from switchgrass using subcritical water. Energy Fuels 2009;23:5151-9.

[63] Cheng L, Ye XP, He R, Liu S. Investigation of rapid conversion of switchgrass in subcritical water. Fuel Process Technol 2009;90:301-11.

[64] Huang H-j Yuan X-z, Zhu H-n Li H, Liu Y, Wang X-l, et al. Comparative studies of thermochemical liquefaction characteristics of microalgae, lignocellulosic biomass and sewage sludge. Energy 2013;56:52-60.

[65] Pińkowska H, Wolak P. Hydrothermal decomposition of rapeseed straw in subcritical water. Proposal of three-step treatment. Fuel 2013;113:340-6.

[66] Adams T, Appel B. Converting turkey offal into bio-derived hydrocarbon oil with the $\{\mathrm{CWT}\}$ thermal process. Power-Gen renewable energy conference; 2004.

[67] Roberts M, Williams J, Halberstadt P, Sanders D, Adams T. Animal Waste to marketable products. Presented at Natural gas technologies II; Ingenuity \& Innovation; February 8-11, 2004, Phoenix, Arizona.

[68] Zheng J-L, Zhu M-Q, Wu H-t. Alkaline hydrothermal liquefaction of swine carcasses to bio-oil. Waste Manag 2015.

[69] Ocfemia KS, Zhang Y, Funk T. Hydrothermal processing of swine manure into oil using a continuous reactor system: development and testing. Trans ASABE 2006;49:533-41.

[70] Yin S, Dolan R, Harris M, Tan Z. Subcritical hydrothermal liquefaction of cattle manure to bio-oil: Effects of conversion parameters on bio-oil yield and characterization of bio-oil. Bioresour Technol 2010;101:3657-64.

[71] Vardon DR, Sharma BK, Scott J, Yu G, Wang Z, Schideman L, et al. Chemical properties of biocrude oil from the hydrothermal liquefaction of Spirulina algae, swine manure, and digested anaerobic sludge. Bioresour Technol 2011;102:8295-303.
[72] Minarick M, Zhang Y, Schideman L, Wang Z, Yu G, Funk T, et al. Product and economic analysis of direct liquefaction of swine manure. Bioenergy Res 2011;4:324-33.

[73] Quitain AT, Sato N, Daimon H, Fujie K. Production of valuable materials by hydrothermal treatment of shrimp shells. Ind Eng Chem Res 2001;40:5885-8.

[74] Yoshida H, Tavakoli O. Sub-critical water hydrolysis treatment for waste squid entrails and production of amino acids, organic acids, and fatty acids. Chem Eng Jpn 2004;37:253-60.

[75] Yoshida H, Takahashi Y, Terashima M. A simplified reaction model for production of oil, amino acids, and organic acids from fish meat by hydrolysis under sub-critical and supercritical conditions. J Chem Eng Jpn 2003;36:441-8.

[76] Akalın MK, Tekin K, Karagöz S. Hydrothermal liquefaction of cornelian cherry stones for bio-oil production. Bioresour Technol 2012:110:682-7.

[77] Salak F, Daneshvar S, Abedi J, Furukawa K. Adding value to onion (Allium cepa L.) waste by subcritical water treatment. Fuel Process Technol 2013;112:86-92.

[78] Wang F, Chang Z, Duan P, Yan W, Xu Y, Zhang L, et al. Hydrothermal liquefaction of Litsea cubeba seed to produce bio-oils. Bioresour Technol 2013;149:509-15.

[79] Liu A, Park Y, Huang Z, Wang B, Ankumah RO, Biswas PK. Product identification and distribution from hydrothermal conversion of walnut shells. Energy Fuels 2006;20:446-54.

[80] Yedro FM, Garcia-Serna J, Cantero DA, Sobron F, Cocero MJ. Hydrotherma hydrolysis of grape seeds to produce bio-oil. RSC Adv 2014;4:30332-9.

[81] Tekin K. Hydrothermal conversion of Russian olive seeds into crude bio-oil using a CaO catalyst derived from waste mussel shells. Energy Fuels 2015.

[82] Chan YH, Yusup S, Quitain AT, Uemura Y, Sasaki M. Bio-oil production from oil palm biomass via subcritical and supercritical hydrothermal liquefaction. Supercrit Fluids 2014;95:407-12.

[83] Kruse A Gawlik A Biomass conversion in water at $330-410{ }^{\circ} \mathrm{C}$ and $30-50 \mathrm{MPa}$. Identification of key compounds for indicating different chemical reaction pathways. Ind Eng Chem Res 2002;42:267-79.

[84] Goto M, Obuchi R, Hirose T, Sakaki T, Shibata M. Hydrothermal conversion of municipal organic waste into resources. Bioresour Technol 2004:93:279-84.

[85] Minowa T, Murakami M, Dote Y, Ogi T, Yokoyama S-y. Oil production from garbage by thermochemical liquefaction. Biomass Bioenergy 1995:8:117-20.

[86] Chiaberge S, Leonardis I, Fiorani T, Bianchi G, Cesti P, Bosetti A, et al. Amides in bio-oil by hydrothermal liquefaction of organic wastes: a mass spectrometric study of the thermochemical reaction products of binary mixtures of amino acids and fatty acids. Energy Fuels 2013;27:5287-97.

[87] Lemoine F, Maupin I, Lemée L, Lavoie JM, Lemberton JL, Pouilloux Y, et al. Alternative fuel production by catalytic hydroliquefaction of solid municipal wastes, primary sludges and microalgae. Bioresour Technol 2013;142:1-8.

[88] Mohan D, Pittman CU, Steele PH. Pyrolysis of wood/biomass for bio-oil: a critical review. Energy Fuels 2006;20:848-89.

[89] Küchen C, Spitzmüller K. Heating Oil. Ullmann's encyclopedia of industrial chemistry. Wiley-VCH Verlag GmbH \& Co. KGaA; 2000.

[90] Xiu S, Shahbazi A, Wallace CW, Wang L, Cheng D. Enhanced bio-oil production from swine manure co-liquefaction with crude glycerol. Energy Convers Manag 2011;52:1004-9.

[91] Toor SS, Rosendahl L, Nielsen MP, Glasius M, Rudolf A, Iversen SB. Continuous production of bio-oil by catalytic liquefaction from wet distiller's grain with solubles (WDGS) from bio-ethanol production. Biomass Bioenergy 2012;36:327-32.

[92] Jena U, Das KC, Kastner JR. Effect of operating conditions of thermochemica liquefaction on biocrude production from Spirulina platensis. Bioresour Technol 2011;102:6221-9.

[93] Methanol Institute. Properties of Fuels: 2014 [November 4, 2014]. Available from: 〈http://www.methanol.org/energy/resources/alternative-fuel/alt-fuelproperties.aspx $\rangle$.

[94] Demirbaş A. Effect of lignin content on aqueous liquefaction products of biomass. Energy Convers Manag 2000:41:1601-7.

[95] Zhong C, Wei X. A comparative experimental study on the liquefaction of wood. Energy 2004;29:1731-41.

[96] Bobleter O. Hydrothermal degradation of polymers derived from plants. Prog Polym Sci 1994;19:797-841.

[97] Teri G, Luo L, Savage PE. Hydrothermal treatment of protein, polysaccharide, and lipids alone and in mixtures. Energy Fuels 2014;28:7501-9.

[98] Sinavg A, Kruse A, Rathert J. Influence of the heating rate and the type of catalyst on the formation of key intermediates and on the generation of gases during hydropyrolysis of glucose in supercritical water in a batch reactor. Ind Eng Chem Res 2003;43:502-8.

[99] Watanabe M, Iida T, Inomata H. Decomposition of a long chain saturated fatty acid with some additives in hot compressed water. Energy Convers Manag 2006;47:3344-50.

[100] Demirbaş A. Mechanisms of liquefaction and pyrolysis reactions of biomass Energy Convers Manag 2000;41:633-46.

[101] He BJ, Zhang Y, Funk TL, Riskowski GL, Yin Y. Thermochemical conversion of swine manure: an alternative process for waste treatment and renewable energy production. Trans Am Soc Agric Eng 2000;43:1827-33.

[102] Zhou D, Zhang L, Zhang S, Fu H, Chen J. Hydrothermal liquefaction of macroalgae enteromorpha prolifera to bio-oil. Energy Fuels 2010;24:4054-61.

[103] Duan P, Savage PE. Hydrothermal liquefaction of a microalga with heterogeneous catalysts. Ind Eng Chem Res 2010;50:52-61. 
[104] Jazrawi C, Biller P, Ross AB, Montoya A, Maschmeyer T, Haynes BS. Pilot plant testing of continuous hydrothermal liquefaction of microalgae. Algal Res 2013;2:268-77.

[105] Duan P, Xu Y, Bai X. Upgrading of crude duckweed bio-oil in subcritical water. Energy Fuels 2013;27:4729-38.

[106] Yin S, Tan Z. Hydrothermal liquefaction of cellulose to bio-oil under acidic neutral and alkaline conditions. Appl Energy 2012;92:234-9.

[107] Biller P, Ross AB. Potential yields and properties of oil from the hydrothermal liquefaction of microalgae with different biochemical content. Bioresour Technol 2011;102:215-25.

[108] Faeth JL, Valdez PJ, Savage PE. Fast hydrothermal liquefaction of Nannochloropsis sp. To produce biocrude. Energy Fuels 2013;27:1391-8.

[109] Valdez PJ, Nelson MC, Faeth JL, Wang HY, Lin XN, Savage PE. Liquefaction of bacteria and yeast monocultures. Energy Fuels 2013;28:67-75.

[110] Valdez PJ, Nelson MC, Wang HY, Lin XN, Savage PE. Hydrothermal liquefaction of Nannochloropsis sp.: systematic study of process variables and analysis of the product fractions. Biomass Bioenergy 2012;46:317-31.

[111] Shuping Z, Yulong W, Mingde Y, Kaleem I, Chun L, Tong J. Production and characterization of bio-oil from hydrothermal liquefaction of microalgae Dunaliella tertiolecta cake. Energy 2010;35:5406-11.

[112] Valdez PJ, Dickinson JG, Savage PE. Characterization of product fractions from hydrothermal liquefaction of Nannochloropsis sp. and the influence of solvents. Energy Fuels 2011;25:3235-43.

[113] Minowa T, Kondo T, Sudirjo ST. Thermochemical liquefaction of indonesian biomass residues. Biomass Bioenergy 1998;14:517-24.

[114] Yang X, Lyu H, Chen K, Zhu X, Zhang S, Chen J. Selective extraction of bio-oil from hydrothermal liquefaction of Salix psammophila by organic solvents with different polarities through multistep extraction separation; 2014

[115] Xu D, Savage PE. Characterization of biocrudes recovered with and without solvent after hydrothermal liquefaction of algae. Algal Res 2014:6(Part A):1-7.

[116] Sasaki M, Fang Z, Fukushima Y, Adschiri T, Arai K. Dissolution and hydrolysis of cellulose in subcritical and supercritical water. Ind Eng Chem Res 2000;39:2883-90.

[117] Sasaki M, Adschiri T, Arai K. Kinetics of cellulose conversion at 25 MPa in suband supercritical water. AIChE J 2004;50:192-202.

[118] Minowa T, Zhen F, Ogi T. Cellulose decomposition in hot-compressed water with alkali or nickel catalyst. J Supercrit Fluids 1998;13:253-9.

[119] Sakaki T, Shibata M, Sumi T, Yasuda S. Saccharification of cellulose using a hot-compressed water-flow reactor. Ind Eng Chem Res 2002;41:661-5.

[120] Rogalinski T, Liu K, Albrecht T, Brunner G. Hydrolysis kinetics of biopolymers in subcritical water. J Supercrit Fluids 2008:46:335-41.

[121] Fang Z, Minowa T, Smith RL, Ogi T, Koziński JA. Liquefaction and gasification of cellulose with $\mathrm{Na}_{2} \mathrm{CO}_{3}$ and $\mathrm{Ni}$ in subcritical water at $350{ }^{\circ} \mathrm{C}$. Ind Eng Chem Res 2004;43:2454-63.

[122] Deguchi S, Tsujii K, Horikoshi K. Cooking cellulose in hot and compressed water. Chem Commun 2006:3293-5.

[123] Deguchi S, Tsujii K, Horikoshi K. Crystalline-to-amorphous transformation of cellulose in hot and compressed water and its implications for hydrothermal conversion. Green Chem 2008;10:191-6.

[124] Kumar S, Gupta RB. Hydrolysis of microcrystalline cellulose in subcritical and supercritical water in a continuous flow reactor. Ind Eng Chem Res 2008; $47: 9321-9$

[125] Srokol Z, Bouche A-G, van Estrik A, Strik RCJ, Maschmeyer T, Peters JA Hydrothermal upgrading of biomass to biofuel; studies on some monosaccharide model compounds. Carbohydr Res 2004;339:1717-26.

[126] Kabyemela BM, Adschiri T, Malaluan RM, Arai K. Kinetics of glucose epimerization and decomposition in subcritical and supercritical water. Ind Eng Chem Res 1997;36:1552-8.

[127] Kabyemela BM, Adschiri T, Malaluan RM, Arai K. Glucose and fructose decomposition in subcritical and supercritical water: detailed reaction pathway, mechanisms, and kinetics. Ind Eng Chem Res 1999;38:2888-95.

[128] Aida TM, Tajima K, Watanabe M, Saito Y, Kuroda K, Nonaka T, et al. Reaction of d-fructose in water at temperatures up to $400{ }^{\circ} \mathrm{C}$ and pressures up to 100 MPa. J Supercrit Fluids 2007:42:110-9.

[129] Aida TM, Sato Y, Watanabe M, Tajima K, Nonaka T, Hattori H, et al. Dehydration of d-glucose in high temperature water at pressures up to $80 \mathrm{MPa}$. J Supercrit Fluids 2007;40:381-8.

[130] Pavlovič I, Knez Z, Skerget M. Subcritical water - a perspective reaction media for biomass processing to chemicals: study on cellulose conversion as a model for biomass. Chem Biochem Eng Q 2013;27:73-82.

[131] Promdej C, Matsumura Y. Temperature effect on hydrothermal decomposition of glucose in sub- and supercritical water. Ind Eng Chem Res 2011;50:8492-7.

[132] Knežević D, van Swaaij WPM, Kersten SRA. Hydrothermal conversion of biomass: I, Glucose conversion in hot compressed water. Ind Eng Chem Res 2009:48:4731-43.

[133] Nelson DA, Hallen T, Richard O. Theander. Formation of aromatic compounds from carbohydrates. pyrolysis oils from biomass. American Chemical Society; 1988. p. $113-18$.

[134] Möller M, Harnisch F, Schroder U. Hydrothermal liquefaction of cellulose in subcritical water-the role of crystallinity on the cellulose reactivity. RSC Adv 2013;3:11035-44.

[135] Rasmussen H, Sørensen HR, Meyer AS. Formation of degradation compounds from lignocellulosic biomass in the biorefinery: sugar reaction mechanisms. Carbohydr Res 2014;385:45-57.
[136] Mok WSL, Antal MJ. Uncatalyzed solvolysis of whole biomass hemicellulose by hot compressed liquid water. Ind Eng Chem Res 1992;31:1157-61.

[137] Ando H, Sakaki T, Kokusho T, Shibata M, Uemura Y, Hatate Y. Decomposition behavior of plant biomass in hot-compressed water. Ind Eng Chem Res 2000;39:3688-93.

[138] Mochidzuki K, Sakoda A, Suzuki M. Liquid-phase thermogravimetric measurement of reaction kinetics of the conversion of biomass wastes in pressurized hot water: a kinetic study. Adv Environ Res 2003;7:421-8.

[139] Sasaki M, Hayakawa T, Arai K, Adschiri T. Measurement of the rate of retroaldol condensation of D-xylose in subcritical and supercritical water. In: Proceedings of the 7th international symposium on hydrothermal reactions. World Scientific Publishing; 2003. p. 169-76.

[140] Antal Jr MJ, Leesomboon T, Mok WS, Richards GN. Mechanism of formation of 2-furaldehyde from d-xylose. Carbohydr Res 1991:217:71-85.

[141] Oefner PJ, Lanziner AH, Bonn G, Bobleter O. Quantitative studies on furfural and organic acid formation during hydrothermal, acidic and alkaline degradation of D-xylose. Monatsh Chem 1992;123:547-56.

[142] Aida TM, Shiraishi N, Kubo M, Watanabe M, Smith Jr RL. Reaction kinetics of d-xylose in sub- and supercritical water. J Supercrit Fluids 2010;55:208-16.

[143] Kabel MA, Carvalheiro F, Garrote G, Avgerinos E, Koukios E, Parajó JC, et al. Hydrothermally treated xylan rich by-products yield different classes of xylooligosaccharides. Carbohydr Polym 2002;50:47-56.

[144] Kumar S. Sub- and supercritical water technology for biofuels. In: Lee JW, editor. Advanced biofuels and bioproducts. New York: Springer; 2013. p. 147-83.

[145] Gao Y, Chen H-p, Wang J, Shi T, Yang H-P, Wang X-H. Characterization of products from hydrothermal liquefaction and carbonation of biomass model compounds and real biomass. J Fuel Chem Technol 2011;39:893-900.

[146] Lora JH, Wayman M. Delignification of hardwoods by autohydrolysis and extraction. AGRICOLA 1978:61.

[147] Bobleter O, Concin R. Degradation of poplar lignin by hydrothermal treatment. Cellulose Chem Technol 1979;13:583-93.

[148] Barbier J, Charon N, Dupassieux N, Loppinet-Serani A, Mahé L, Ponthus J, et al. Hydrothermal conversion of lignin compounds. A detailed study of fragmentation and condensation reaction pathways. Biomass Bioenergy 2012;46:479-91.

[149] Wahyudiono Sasaki M. Goto M. Recovery of phenolic compounds through the decomposition of Lignin in near and supercritical water. Chem Eng Process: Process Intensif 2008;47:1609-19.

[150] Okuda K, Umetsu M, Takami S, Adschiri T. Disassembly of lignin and chemical recovery - rapid depolymerization of lignin without char formation in water-phenol mixtures. Fuel Process Technol 2004;85:803-13.

[151] Fang Z, Sato T, Smith Jr RL, Inomata H, Arai K, Kozinski JA. Reaction chemistry and phase behavior of Lignin in high-temperature and supercritical water. Bioresour Technol 2008;99:3424-30.

[152] Zhang B, Huang H-J, Ramaswamy S. Reaction kinetics of the hydrothermal treatment of lignin. Appl Biochem Biotechnol 2008;147:119-31.

[153] Erdocia X, Prado R, Angeles Corcuera M, Labidi J. Base catalyzed depolymerization of lignin: Influence of organosolv lignin nature. Biomass Bioenergy 2014;66:379-86.

[154] Wahyudiono Kanetake T, Sasaki M, Goto M. Decomposition of a Lignin model compound under hydrothermal conditions. Chem Eng Technol 2007:30:1113-22.

[155] Wahyudiono Sasaki M, Goto M. Conversion of biomass model compound under hydrothermal conditions using batch reactor. Fuel 2009;88:1656-64.

[156] Lawson JR, Klein MT. Influence of water on guaiacol pyrolysis. Ind Eng Chem Fundam 1985;24:203-8.

[157] Sato T, Sekiguchi G, Saisu M, Watanabe M, Adschiri T, Arai K. Dealkylation and rearrangement kinetics of 2-isopropylphenol in supercritical water. Ind Eng Chem Res 2002;41:3124-30.

[158] Kang S, Li X, Fan J, Chang J. Classified separation of Lignin hydrothermal liquefied products. Ind Eng Chem Res 2011;50:11288-96.

[159] Yong TL-K Matsumura Y. Kinetic analysis of Lignin hydrothermal conversion in sub- and supercritical water. Ind Eng Chem Res 2013:52:5626-39.

[160] Okuda K, Ohara S, Umetsu M, Takami S, Adschiri T. Disassembly of lignin and chemical recovery in supercritical water and p-cresol mixture: studies on lignin model compounds. Bioresour Technol 2008;99:1846-52.

[161] Yang L, Li Y, Savage PE. Hydrolytic cleavage of C-O linkages in Lignin model compounds catalyzed by water-tolerant lewis acids. Ind Eng Chem Res 2014;53:2633-9.

[162] Yoshida K, Kusaki J, Ehara K, Saka S. Characterization of low molecular weight organic acids from beech wood treated in supercritical water. Appl Biochem Biotechnol 2005;123:795-806.

[163] Ehara K, Saka S, Kawamoto H. Characterization of the lignin-derived products from wood as treated in supercritical water. J Wood Sci 2002;48:320-5.

[164] Yong TL-K Matsumura Y. Reaction kinetics of the Lignin conversion in supercritical water. Ind Eng Chem Res 2012;51:11975-88.

[165] Saisu M, Sato T, Watanabe M, Adschiri T, Arai K. Conversion of Lignin with supercritical water-phenol mixtures. Energy Fuels 2003;17:922-8.

[166] Osada M, Sato O, Watanabe M, Arai K, Shirai M. Water density effect on lignin gasification over supported noble metal catalysts in supercritical water. Energy Fuels 2006;20:930-5.

[167] Pourali O, Asghari FS, Yoshida H. Production of phenolic compounds from rice bran biomass under subcritical water conditions. Chem Eng J 2010;160:259-66. 
[168] Patil PT, Armbruster U, Martin A. Hydrothermal liquefaction of wheat straw in hot compressed water and subcritical water-alcohol mixtures. J Supercrit Fluids 2014:93:121-9.

[169] Yuan XZ, Li H, Zeng GM, Tong JY, Xie W. Sub- and supercritical liquefaction of rice straw in the presence of ethanol-water and 2-propanol-water mixture. Energy 2007;32:2081-8.

[170] Toledano A, Serrano L, Labidi J. Improving base catalyzed lignin depolymerization by avoiding lignin repolymerization. Fuel 2014;116:617-24.

[171] Yan N, Zhao C, Dyson PJ, Wang C, Liu L-t, Kou Y. Selective degradation of wood Lignin over noble-metal catalysts in a two-step process. ChemSusChem 2008;1:626-9.

[172] Quitain AT, Daimon H, Fujie K, Katoh S, Moriyoshi T. Microwave-assisted hydrothermal degradation of silk protein to amino acids. Ind Eng Chem Res 2006; 45:4471-4.

[173] Abdelmoez W, Nakahasi T, Yoshida H. Amino acid transformation and decomposition in saturated subcritical water conditions. Ind Eng Chem Res 2007;46:5286-94.

[174] Yoshida H, Terashima M, Takahashi Y. Production of organic acids and amino acids from fish meat by sub-critical water hydrolysis. Biotechnol Prog 1999; 15:1090-4.

[175] Kang K, Quitain AT, Daimon H, Noda R, Goto N, Hu H-Y, et al. Optimization of amino acids production from waste fish entrails by hydrolysis in sub and supercritical water. Can J Chem Eng 2001;79:65-70.

[176] Cheng H, Zhu X, Zhu C, Qian J, Zhu N, Zhao L, et al. Hydrolysis technology of biomass waste to produce amino acids in sub-critical water. Bioresour Technol 2008;99:3337-41.

[177] Sereewatthanawut I, Prapintip S, Watchiraruji K, Goto M, Sasaki M, Shotipruk A. Extraction of protein and amino acids from deoiled rice bran by subcritical water hydrolysis. Bioresour Technol 2008;99:555-61.

[178] Pinkowska H, Oliveros E. Application of Doehlert matrix for determination of the optimal conditions of hydrolysis of soybean protein in subcritical water. Ind Eng Chem Res 2014;53:1320-6.

[179] Rogalinski T, Herrmann S, Brunner G. Production of amino acids from bovine serum albumin by continuous sub-critical water hydrolysis. J Supercrit Fluids 2005;36:49-58.

[180] Abdelmoez W Yoshida H. Production of amino and organic acids from protein using sub-critical water technology. Int J Chem React Eng 2013;11:1-16.

[181] Qian Y, Engel MH, Macko SA, Carpenter S, Deming JW. Kinetics of peptide hydrolysis and amino acid decomposition at high temperature. Geochim Cosmochim Acta 1993;57:3281-93.

[182] Li J, Wang X, Klein MT, Brill TB. Spectroscopy of hydrothermal reactions, 19: $\mathrm{pH}$ and salt dependence of decarboxylation of $\alpha$-alanine at $280-330^{\circ} \mathrm{C}$ in an FT-IR spectroscopy flow reactor. Int J Chem Kinet 2002;34:271-7.

[183] Sato N, Quitain AT, Kang K, Daimon H, Fujie K. Reaction kinetics of amino acid decomposition in high-temperature and high-pressure water. Ind Eng Chem Res 2004;43:3217-22.

[184] Klingler D, Berg J, Vogel H. Hydrothermal reactions of alanine and glycine in sub- and supercritical water. J Supercrit Fluids 2007:43:112-9.

[185] Andersson E, Holm N. The stability of some selected amino acids under attempted redox constrained hydrothermal conditions. Orig Life Evol Biosph 2000;30:9-23.

[186] Dote Y, Inoue S, Ogi T, Yokoyama S-y. Studies on the direct liquefaction of protein-contained biomass: The distribution of nitrogen in the products. Biomass Bioenergy 1996;11:491-8.

[187] Dote Y, Inoue S, Ogi T, Yokoyama S-y. Distribution of nitrogen to oil products from liquefaction of amino acids. Bioresour Technol 1998;64:157-60.

[188] Mills VH, McClain K. Fat hydrolysis. Ind Eng Chem 1949;41:1982-5.

[189] Milliren AL, Wissinger JC, Gottumukala V, Schall CA. Kinetics of soybean oil hydrolysis in subcritical water. Fuel 2013:108:277-81.

[190] Johnson MC, Tester JW. Lipid transformation in hydrothermal processing of whole algal cells. Ind Eng Chem Res 2013;52:10988-95.

[191] Krammer P, Vogel H. Hydrolysis of esters in subcritical and supercritical water. J Supercrit Fluids 2000;16:189-206.

[192] Oka H, Yamago S, Yoshida J, Kajimoto O. Evidence for a hydroxide ion catalyzed pathway in ester hydrolysis in supercritical water. Angew Chem Int Ed 2002;41:623-5.

[193] Comisar CM, Hunter SE, Walton A, Savage PE. Effect of pH on ether, ester, and carbonate hydrolysis in high-temperature water. Ind Eng Chem Res 2007; $47: 577-84$

[194] Changi S, Pinnarat T, Savage PE. Mechanistic modeling of hydrolysis and esterification for biofuel processes. Ind Eng Chem Res 2011;50:12471-8.

[195] Changi S, Pinnarat T, Savage PE. Modeling hydrolysis and esterification kinetics for biofuel processes. Ind Eng Chem Res 2011;50:3206-11.

[196] Sturzenegger A, Sturm H. Hydrolysis of fats at high temperatures. Ind Eng Chem 1951:43:510-5.

[197] Lascaray L. Industrial fat splitting. J Am Oil Chem Soc 1952;29:362-6.

198] Patil TA, Butala DN, Raghunathan TS, Shankar HS. Thermal hydrolysis of vegetable oils and fats. 1. Reaction kinetics. Ind Eng Chem Res 1988;27:727-35.

[199] Patil TA, Raghunathan TS, Shankar HS. Thermal hydrolysis of vegetable oils and fats. 2. Hydrolysis in continuous stirred tank reactor. Ind Eng Chem Res 1988;27:735-9.

[200] Fu J, Lu X, Savage PE. Hydrothermal decarboxylation and hydrogenation of fatty acids over Pt/C. ChemSusChem 2011;4:481-6.

[201] Pinto JSS, Lanças FM. Hydrolysis of corn oil using subcritical water. J Braz Chem Soc 2006:17:85-9.
[202] Wang Z. Reaction Mechanisms of hydrothermal liquefaction of model compounds and biowaste feedstocks. University of Illinois at Urbana-Champaign 2011.

[203] Long Y-D, Fang Z. Hydrothermal conversion of glycerol to chemicals and hydrogen: review and perspective. Biofuels Bioprod Biorefining 2012;6:686-702.

[204] Xiu S, Shahbazi A, Shirley V, Mims MR, Wallace CW. Effectiveness and mechanisms of crude glycerol on the biofuel production from swine manure through hydrothermal pyrolysis. J Anal Appl Pyrolysis 2010;87:194-8.

[205] Xiu S, Shahbazi A, Shirley VB, Wang L. Swine manure/Crude glycerol coliquefaction: physical properties and chemical analysis of bio-oil product. Bioresour Technol 2011;102:1928-32.

[206] Ye Z, Xiu S, Shahbazi A, Zhu S. Co-liquefaction of swine manure and crude glycerol to bio-oil: model compound studies and reaction pathways. Bioresour Technol 2012;104:783-7.

[207] Minowa T, Inoue S, Hanaoka T, Matsumura Y. Hydrothermal reaction of glucose and glycine as model compounds of biomass. Nihon Enerugi Gakkaishi/J Jpn Inst Energy 2004;83:794-8.

[208] Inoue S, Noguchi M, Hanaoka T, Minowa T, Organic compounds formed by thermochemical degradation of glucose-glycine melanoidins using hot compressed water. J Chem Eng Jpn 2004;37:915-9.

[209] Peterson AA, Lachance RP, Tester JW. Kinetic evidence of the maillard reaction in hydrothermal biomass processing: glucose - glycine interactions in high-temperature, high-pressure water. Ind Eng Chem Res 2010;49:2107-17.

[210] Kruse A, Krupka A, Schwarzkopf V, Gamard C, Henningsen T. Influence of proteins on the hydrothermal gasification and liquefaction of biomass. 1 . Comp Differ Feedstocks Ind Eng Chem Res 2005;44:3013-20.

[211] Changi S, Zhu M, Savage PE. Hydrothermal reaction kinetics and pathways of phenylalanine alone and in binary mixtures. ChemSusChem 2012;5:1743-57.

[212] Yoshida T, Matsumura Y. Gasification of cellulose, Xylan, and Lignin mixtures in supercritical water. Ind Eng Chem Res 2001;40:5469-74.

[213] Osada M, Sato T, Watanabe M, Adschiri T, Arai K. Low-temperature catalytic gasification of lignin and cellulose with a ruthenium catalyst in supercritica water. Energy Fuels 2003;18:327-33.

[214] Weiss-Hortala E, Kruse A, Ceccarelli C, Barna R. Influence of phenol on glucose degradation during supercritical water gasification. J Supercrit Fluids 2010;53:42-7.

[215] Elliott DC, Beckman D, Bridgwater AV, Diebold JP, Gevert SB, Solantausta Y Developments in direct thermochemical liquefaction of biomass: 1983-1990. Energy Fuels 1991;5:399-410.

[216] Behrendt F, Neubauer Y, Oevermann M, Wilmes B, Zobel N. Direct liquefaction of biomass. Chem Eng Technol 2008;31:667-77.

[217] Elliott DC. Hydrothermal processing. Thermochemical processing of biomass. John Wiley \& Sons, Ltd; 2011. p. 200-31.

[218] Elliott DC. Process Development for Biomass Liquefaction. American Chemical Society Division of Fuel Chemistry 1980;25:257-63.

[219] Green Car Congress. NextFuels introduces hydrothermal process to produce biofuels from wet, unprocessed waste; solution for palm plantation residu; 2013 [October 24, 2014]. Available from: 〈http://www.greencarcongress.com/ 2013/08/20130819-next.html

[220] Goudriaan F, van de Beld B, Boerefijn FR, Bos GM, Naber JE, van der Wal S, et al. Thermal efficiency of the HTU ${ }^{\mathbb{R}}$ process for biomass liquefaction. Progress in thermochemical biomass conversion. Blackwell Science Ltd; 2008. p. $1312-25$

[221] Nielsen RP, Olofsson G, Søgaard EG. CatLiq - high pressure and temperature catalytic conversion of biomass: The CatLiq technology in relation to other thermochemical conversion technologies. Biomass Bioenergy 2012;39:399-402.

[222] Altaca. CatLiq ${ }^{\mathbb{B}}$ (Catalytic Liquidification) Technology; 2014 [April 28, 2014]. Available from: 〈http://www.altaca.com/index_pages_22.html).

[223] The Carthage Press. Canadian firm acquires Carthage RES plant; 2013 [February 10, 2015]. Available from: 〈http://www.carthagepress.com/article/ 20130416/NEWS/130419181/1001/NEWS?rssfeed true>.

[224] Worldwide BioEnergy. Thermal Chemical Conversion; 2014 [May 20, 2014] Available from: 〈http://wwbioenergy.biz/ $\rangle$.

[225] Molton PM, Fassbender AG, Brown MD. Stors: the sludge-to-oil reactor system; 1986.

[226] Itoh S, Suzuki A, Nakamura T, Yokoyama S-y. Production of heavy oil from sewage sludge by direct thermochemical liquefaction. Desalination 1994;98:127-33.

[227] Thermo Energy. Municipal Markets-Ammonia Removal and Recovery; 2014 [2014. May 19th]. Available from: 〈http://www.thermoenergy.com/waste water-recovery/applications/ammonia-removal-recovery>.

[228] Mørup AJ, Becker J, Christensen PS, Houlberg K, Lappa E, Klemmer M, et al, Construction and commissioning of a continuous reactor for hydrothermal liquefaction. Ind Eng Chem Res 2015;54:5935-47.

[229] Elliott DC, Hart TR, Schmidt AJ, Neuenschwander GG, Rotness LJ, Olarte MV, et al. Process development for hydrothermal liquefaction of algae feedstocks in a continuous-flow reactor. Algal Res 2013;2:445-54.

[230] Elliott DC, Hart TR, Neuenschwander GG, Rotness LJ, Roesijadi G, Zacher AH, et al. Hydrothermal processing of macroalgal feedstocks in continuous-flow reactors. ACS Sustain Chem Eng 2013;2:207-15.

[231] Hognon C, Delrue F, Texier J, Grateau M, Thiery S, Miller H, et al. Comparison of pyrolysis and hydrothermal liquefaction of Chlamydomonas reinhardtii. Growth studies on the recovered hydrothermal aqueous phase. Biomass Bioenergy 2015;73:23-31. 
[232] Garcia Alba L, Torri C, Fabbri D, Kersten SRA, Brilman DWF. Microalgae growth on the aqueous phase from Hydrothermal Liquefaction of the same microalgae. Chem Eng J 2013;228:214-23.

[233] Zhu Z, Rosendahl L, Toor SS, Yu D, Chen G. Hydrothermal liquefaction of barley straw to bio-crude oil: Effects of reaction temperature and aqueous phase recirculation. Appl Energy 2015;137:183-92.

[234] Ramos-Tercero EA, Bertucco A, Brilman DWF. Process water recycle in hydrothermal liquefaction of microalgae to enhance bio-oil yield. Energy Fuels 2015;29:2422-30.

[235] Wirth B, Mumme J. Anaerobic digestion of waste water from hydrothermal carbonization of corn silage. Appl Bioenergy 2013:1.

[236] Danso-Boateng E, Shama G, Wheatley AD, Martin SJ, Holdich RG. Hydrothermal carbonisation of sewage sludge: effect of process conditions on product characteristics and methane production. Bioresour Technol 2015; 177:318-27.
[237] Zhu Y, Biddy MJ, Jones SB, Elliott DC, Schmidt AJ. Techno-economic analysis of liquid fuel production from woody biomass via hydrothermal liquefaction (HTL) and upgrading. Appl Energy 2014;129:384-94.

[238] Mo N, Savage PE. Hydrothermal catalytic cracking of fatty acids with HZSM5. ACS Sustain Chem Eng 2013;2:88-94.

[239] Santillan-Jimenez E, Morgan T, Lacny J, Mohapatra S, Crocker M. Catalytic deoxygenation of triglycerides and fatty acids to hydrocarbons over carbonsupported nickel. Fuel 2013;103:1010-7.

[240] Fu J, Lu X, Savage PE. Catalytic hydrothermal deoxygenation of palmitic acid. Energy Environ Sci 2010;3:311-7.

[241] Biller P, Riley R, Ross AB. Catalytic hydrothermal processing of microalgae: decomposition and upgrading of lipids. Bioresour Technol 2011;102:4841-8.

[242] Duan P, Savage PE. Catalytic hydrothermal hydrodenitrogenation of pyridine. Appl Catal B: Environ 2011;108-109:54-60.

[243] http://steeperenergy.com/. 